\title{
Administration of C5a Receptor Antagonist Improves the Efficacy of Human iPSCS-derived NS/PC Transplantation in the Acute Phase Of spinal Cord Injury
}

\section{Reo Shibata}

Keio University School of Medicine https://orcid.org/0000-0002-4204-4058

Narihito Nagoshi ( $\square$ nagoshi@keio.jp)

https://orcid.org/0000-0001-8267-5789

Keita Kajikawa

Keio University School of Medicine

Shuhei Ito

Keio University School of Medicine

Mohamad Khazaei

Krembil Research Institute, University Health Network

Satoshi Nori

Keio University School of Medicine

Jun Kohyama

Keio University School of Medicine

Michael G. Fehlings

Krembil Research Institute, University Health Network

Morio Matsumoto

Keio University School of Medicine

Masaya Nakamura

Keio University School of Medicine

Hideyuki Okano

Keio University School of Medicine

\section{Research}

Keywords: Spinal cord injury, human-induced pluripotent stem cells derived neural stem/progenitor cell (hiPSC-NS/PC), C5a, acute phase, cell survival

Posted Date: July 6th, 2020 
DOI: https://doi.org/10.21203/rs.3.rs-39369/v1

License: (c) (1) This work is licensed under a Creative Commons Attribution 4.0 International License. Read Full License

Version of Record: A version of this preprint was published at Journal of Neurotrauma on February 24th, 2022. See the published version at https://doi.org/10.1089/neu.2021.0225. 


\section{Abstract}

Background: We previously reported the efficacy of human-induced pluripotent stem cells derived neural stem/progenitor cells (hiPSC-NS/PCs) transplantation for spinal cord injury (SCI) in the subacute phase. However, this procedure is not effective in the acute phase due to the inflammatory response occurring immediately after $\mathrm{SCl}$, which negatively impacts transplanted cell survival. $\mathrm{C5a}$, which is one of the complement components, is a powerful chemoattractant which recruits inflammatory cells through binding of the $\mathrm{C} 5 \mathrm{a}$ receptor. We hypothesized that suppression of the inflammatory response immediately after $\mathrm{SCl}$ using a C5a receptor antagonist (C5aRA) as an immunosuppressant would improve the efficacy of hiPSC-NS/PCs transplantation for SCl in the acute phase.

Methods: Immunodeficient SCID-Beige mice underwent contusion SCI at T10 and received C5aRA immediately after SCl. Inflammatory cytokines and inflammatory cells in the injured spinal cord tissue during the acute phase were quantified using quantitative PCR and flow-cytometry. Next, we randomly and blindly divided the SCl mice into 4 groups (PBS only, C5aRA only, PBS + transplantation (PBS+TP), C5aRA + transplantation (C5aRA+TP)). Immediately after SCl, C5aRA or PBS was injected intraperitoneally once a day for 4 consecutive days, and then, $5.0 \times 10^{5}$ hiPSC-NS/PCs were transplanted into the lesion epicenter on day 4 in the PBS+TP and C5aRA+TP groups. We evaluated cell survival rate, hindlimb motor function, and the differentiation profile of the graft hiPSC-NS/PCs.

Results: C5aRA administration significantly reduced several inflammatory cytokines such as IL-1b, IL-6 and TNFa, as well as inflammatory cells after SCl. Within the transplantation groups, the C5aRA+TP group had better functional improvement as compared to the PBS only group. The C5aRA+TP group also had a significantly higher cell survival rate compared to the PBS+TP group. There were no significant differences in the differentiation profiles of grafted hiPSC-NS/PCs between the C5aRA+TP and PBS+TP groups.

Conclusion: This study demonstrates that administration of C5aRA can suppress the inflammatory response during the acute phase of $\mathrm{SCl}$, and also improve the survival rate of transplanted hiPSC-NS/PCs as well as enhance motor functional restoration. hiPSC-NS/PC transplantation with C5aRA is a promising treatment during the acute injury phase for SCl patients.

\section{Background}

A proportion of individuals who sustain a spinal cord injury ( $\mathrm{SCl}$ ) will suffer from lifelong and severe motor and sensory dysfunction, due to the body's limited ability for neurologic recovery post-injury[1]. To enhance recovery, much attention has been focused on cell transplantation therapies for SCl, especially the use of human-induced pluripotent stem cell (hiPSC). Indeed, we and other groups have demonstrated the efficacy of hiPSC-derived neural stem/progenitor cell (hiPSC-NS/PC) transplantation for conferring functional recovery in $\mathrm{SCl}[2-4]$, and these advancements are expected to reach clinical application in the near future [5]. 
However, critical issues remain surrounding the timing of cell transplantation and optimization of the injury site milieu. Currently, the optimal timing for transplantation is the subacute phase of $\mathrm{SCl}$, which is about 7-14 days after $\mathrm{SCl}$ in rodents, after neuroinflammation subsides. Since the inflammatory reaction in the acute phase of injury does not allow transplanted cells to survive, researchers have been forced to wait until the subacute phase to transplant cells $[6,7]$. During the acute phase of injury, several neurotoxic cytokines are upregulated and inflammatory cells intrude into the lesion area [8, 9]. As a consequence of this heightened inflammatory response, there is significant host cell death and a diminished ability for the spinal cord to recover, and thereby, functional improvement is limited even after cell transplantation. However, if this harmful inflammatory response were to be suppressed immediately after the injury, a favorable environment for the grafted cells could be created, and moreover, it may be possible to perform cell transplantation in the acute phase.

The complement system has a very important role in initiating secondary damage during the acute phase in SCl. The complement proteins activate various neurotoxic cytokines and inflammatory cells, and this complex inflammatory cascade lead to the exacerbation of neural damage [10-13]. Thus, the inflammation process is principally triggered by the complements, and among these proteins, C5a has recently received attention as a target of anti-inflammatory treatment. C5a is a small glycoprotein (74 amino acids, about $11 \mathrm{kDa}$ ) and generated by the cleaving of complement C5 [12]. C5a is an anaphylatoxin, which causes inflammatory cytokine activation and leukocyte infiltration through the C5a receptor (C5aR) [14]. Consequently, C5aR antagonist (C5aRA) could be a target as a treatment for inflammatory reaction after SCl. Among C5aRA, PMX205 (hydrocinnamate- (OPdChaWR)) is often used in the field of CNS disease experiment because PMX205 is able to penetrate blood-brain barrier and blood-spinal cord barrier $[15,16]$, and it has been shown that PMX205 administration after SCI suppresses inflammatory cytokines and macrophage infiltration into the lesion, decreases secondary damage, and improves the recovery of locomotor function [17]. These studies indicate that administration of C5aRA can inhibit the inflammatory reaction during the acute phase of $\mathrm{SCl}$ and prepare the injured microenvironment for receiving transplanted NS/PCs.

The purpose of the current study is to investigate whether C5aRA improves the inflammatory environment and enables increased survival of grafted cells when transplanted during the acute phase after $\mathrm{SCl}$. We also evaluated the impact of a combined therapy of hiPSC-NS/PCs transplantation and C5aRA on locomotor functional recovery.

This study is particularly important as it is the first study to our knowledge which demonstrates immunosuppressant enables efficient hiPSC-NS/PCs transplantation during acute phase after SCl by increasing survival of grafted cells.

\section{Materials And Methods}

\section{Animals}


Adult female SCID-Beige mice (8-10 weeks, 17-22 g), which are deficient in lymphocytes and NK cells, were provided by Charles River Laboratory. All animals were housed in a temperature- and humiditycontrolled environment. All experimental procedures were approved by the ethics committee of Keio University (Assurance No. 13020) and were in accordance with the Guide for the Care and Use of Laboratory Animals (National Institutes of Health, Bethesda, MD, USA). The number of mice used in this study is shown in Supplemental File 1.

\section{Spinal cord injury}

The mice were anesthetized with ketamine $(60 \mathrm{mg} / \mathrm{kg})$ and xylazine $(10 \mathrm{mg} / \mathrm{kg})$ intraperitoneally. Laminectomy was performed at the 10th thoracic spinal vertebra (T10), and the dorsal surface of the dura matter was exposed. Moderate (70 kdyn) contusion injury was induced at the level of T10 using an Infinite Horizon impactor (Precision Systems and Instrumentation, Fairfax Station, VA), as previously described [18]. The muscles were sutured and the skin was closed with wound clips. After spinal cord injury, ampicillin $(12.5 \mathrm{mg} / \mathrm{kg})$ was administrated subcutaneously.

\section{C5a ELISA}

A total of 25 mice were used in this experiment; the injured mice were sacrificed at 4 times $(n=5 /$ each survival time) with 5 naive controls. The times included 1, 4, 7, and 14 days post-injury. The mice were anesthetized with ketamine $(60 \mathrm{mg} / \mathrm{kg})$ and xylazine $(10 \mathrm{mg} / \mathrm{kg})$ intraperitoneally and transcardially perfused with PBS. Six millimeters of spinal cord, centered at the lesion epicenter, were dissected and immediately frozen in liquid nitrogen. As a control, samples of naïve spinal cords were harvested using the same protocol $(N=5)$. Dissected spinal cords were homogenized in lysis buffer with phosphatase and protease inhibitors and centrifuged at $10000 \times \mathrm{g}$ for $5 \mathrm{~min}$. The supernatants were collected and protein concentration was evaluated using a Bradford assay. C5a concentration was determined using the ELISA kit (R\&D system) according to the manufacturer's instructions.

\section{C5a receptor western blotting}

A total of 16 mice were used in this experiment; the injured mice were sacrificed at 3 times $(n=4$ /each survival time) with 4 naive controls. The times included 1, 4, and 7 days post-injury. Spinal cords centered at the lesion were dissected, as mentioned previously. Dissected spinal cords were homogenized in lysis buffer with phosphatase and protease inhibitors and centrifuged. The supernatant was dissolved in $4 \times$ Laemmli sample buffer and heat-denatured at $95^{\circ} \mathrm{C}$ for $5 \mathrm{~min}$. As a control, samples of naïve spinal cords were harvested using the same protocol $(\mathrm{N}=4)$. Samples were electrophoretically dissociated on $10 \%$ SDS-PAGE and transferred to membrane as described [19]. The membranes were blocked for $1 \mathrm{~h}$ at room temperature with block solution (Blocking one, nacalai tesque, Japan) and incubated with diluted C5aR antibody (1:1000, Rat, Bio-Rad, USA) at $4{ }^{\circ} \mathrm{C}$ overnight. After, the membranes were subjected to a reaction with HRP-conjugated anti-rat IgG at room temperature for $1 \mathrm{~h}$. After the membranes were washed, the HRP activity was detected using an ECL kit. The image was scanned with the ImageQuant LAS4000 mini (GE Healthcare Life Sciences, USA), and the data were analyzed using ImageJ. $\beta$-actin (1:2000, Rat) was used as an internal control. 


\section{C5a receptor antagonist administration}

We used PMX205 (Tocris Bioscience, England) as a C5a receptor antagonist, as previously reported [17]. Immediately after SCl, the mice randomly received PMX205(1 mg/kg body weight) [17] diluted in $1 \%$ ethanol or PBS containing $1 \%$ ethanol intraperitoneally once a day for 4 consecutive days, or until sacrificed.

\section{quantitative RT-PCR}

A total of 50 mice were used in this experiment; the injured mice were sacrificed at 4 times (C5aRA group; $\mathrm{N}=4$ each time point, PBS group; $\mathrm{N}=5$ each time point) with 5 naive controls. The times included $6 \mathrm{~h}$, $12 \mathrm{~h}, 1$ day, and 4 days after SCl. Six mm spinal cord sections centered at the lesion were harvested and immediately frozen in liquid nitrogen (C5aRA group; $\mathrm{N}=4$ each time point, PBS group; $\mathrm{N}=5$ each time point). Total RNA was isolated from the frozen spinal cords using the RNeasy Mini Kit (Qiagen Inc., Hilgen, Germany), in accordance with the manufacturer's instructions. As a control, total RNA was isolated from naïve spinal cords by the same protocol $(N=5)$. A reverse transcription reaction was performed using Reverse transcriptase kit (ReverTra Ace; Toyobo, Japan). RT-PCR was performed using primers specific to the genes of interest and TaqMan Fast Advanced Master Mix (Thermo Fischer Scientific, USA). The data were normalized to the expression level of $\beta$-actin (ACTB).

The following manufactured primers (Applied Biosystems; http://www.appliedbiosystems.com) against mouse DNA sequences were used: interleukin-1 $\beta$ (II1 $\beta$ )-Mm00434228_m1, interleukin-6 (II6)Mm00446190_m1, TNF-Mm00443258_m1, ACTB-Mm02619580_g1.

\section{mRNA-Seq}

A total of 22 mice were used in this experiment; the injured mice were sacrificed at 4 times (C5aRA group; $\mathrm{N}=2$ each time point, PBS group; $\mathrm{N}=2$ each time point) with 2 naive controls. The times included $3 \mathrm{~h}, 6 \mathrm{~h}$, $12 \mathrm{~h}, 1$ day, and 4 days after SCl. Six mm spinal cord sections centered the lesion were harvested and samples were processed for RNA preparation and library preparation for mRNA-SEq. Samples for mRNASeq were prepared using the TruSeq RNA Sample Prep Kit (Illumina) in accordance with the manufacture's instructions. As a control, samples were prepared from naïve spinal cords using the same procedure. The sequencing library was sequenced with the HiSeq 2500 (Illumina). Base-calling and chastity filtering were performed using Real-Time Analysis Software version 1.18.61 and raw reads were mapped to reference genome $\mathrm{mm} 9$ using Sailfish (v0.7.6) with default settings. All gene expression profiles were evaluated using Exatlas (https://lgsun.irp.nia.nih.gov/exatlas/). The extracted data were visualized with Morpheus (https://software.broadinstitute.org/morpheus).

\section{Flow cytometry}

After the mice were transcardially perfused with PBS, $6 \mathrm{~mm}$ spinal cord sections centered at the lesion were harvested (Neutrophils; $\mathrm{N}=6$ each group, Macrophage; $\mathrm{N}=6$ each group), digested with collagenase (Accumax; Innovative cell technologies, USA), and passed through a wire mesh screen (Sigma-Aldrich 
Canada Ltd., Canada) to acquire a single-cell suspension. The cells were incubated on ice for 30 min with Fc blocker followed by an additional 30 min on ice with fluorescent antibodies. To exclude the dead cells, 7-AAD was added. Flow cytometric analysis was carried out using a FACS Verse (Becton Dickinson, USA), and the data were analyzed using Cell Quest software. The samples were immunolabeled with rat antiCD11b-BV421 (1:200; BD Horizon, USA), rat anti-LY6G-PE (1:200; BD Horizon, USA) and rat anti-CD45-APC (1:200; BD Horizon, USA). Macrophages were defined as CD45 high CD11 $\mathrm{b}^{+}$LY6G- population, and neutrophils were defined as $\mathrm{CD} 45^{\text {high }} \mathrm{CD} 11 \mathrm{~b}-\mathrm{LY}_{6 \mathrm{G}}{ }^{+}$population.

\section{Cell culture, lentivirus transduction}

Cell culture of hiPSC (414C2) was performed as described previously, with subtle modifications [20]. Briefly, hiPSC grown on gelatin-coated $(0.1 \%)$ tissue culture dishes were used for EB formation. EBs were then enzymatically dissociated into single cells and cultured in serum-free media hormone mix (MHM) for 10-12 days to allow the formation of neurospheres. Neurospheres were dissociated into single cells and cultured in the same method for passage. A lentivirus that expressed ffLuc, which is a fusion protein consisting of yellow variant of Aequorea GFP and a firefly luciferase [21] under the control of an EF promoter to enable the detection of the grafted cells in living mice and in fixed sections, was prepared [22], and transduced into hiPSC-NS/PCs as previously described [2].

Neural differentiation and immunohistochemistryDissociated third-passage ffLuc induced NS/PCs (1.0 $\times$ 105 well) were plated in poly-L-ornithine /fibronectin coated 8 well chamber slides (Thermo Fischer Scientific, USA), and PMX205 (20 $\mu \mathrm{g} /$ well) or PBS was added to each chamber. These cells were cultured in medium without growth factors at $37^{\circ} \mathrm{C}$ under $5 \% \mathrm{CO} 2$ for 14 days in total. Differentiated cells were fixed at $0.1 \mathrm{M}$ PBS containing $4 \%$ PFA and stained with the following primary antibodies overnight at $4{ }^{\circ} \mathrm{C}$; anti-ßIII Tubulin (mouse IgG2b, 1:300; SIGMA, T8660), anti-O4 (mouse IgM, 1:200; Thermo Fischer, MAB1326) and anti-GFAP (Rabbit, 1:2000; Proteintech, AG10423). These sections were incubated with Alexa Fluor 488-, 555-, or 647-conjugated secondary antibodies (Thermo Fisher Scientific, USA), and Hoechst $33258(10 \mu \mathrm{g} / \mathrm{ml}$, Sigma-Aldrich) as a nuclear counterstaining. All images were obtained using a fluorescence microscope (BZ 9000; Keyence Co., Japan) or a confocal laser scanning microscope (LSM 700; Carl Zeiss, Germany). For quantification of BIII Tubulin-, 04-, and GFAP-positive cells, five regions within the chamber were randomly selected and counted under $\times 40$ magnification.

\section{Cell transplantation}

Four days after $\mathrm{SCl}$, the mice were randomly and blindly divided into four groups based on their BMS score to ensure equivalent deficits across the groups: (PBS only group, C5aRA only group, PBS + transplantation (PBS + TP) group, C5aRA + transplantation (C5aRA + TP) group), and re-anesthetized with isoflurane. hiPSC- NS/PCs $\left(5 \times 10^{5} \mathrm{cells} / 2 \mu \mathrm{I}\right)$ or PBS were transplanted into the lesion epicenter using a metal needle at a rate of $1 \mu \mathrm{l} /$ minute (PBS only; $\mathrm{N}=20, \mathrm{C} 5 \mathrm{aRA}$ only; $\mathrm{N}=19, \mathrm{PBS}+\mathrm{TP} ; \mathrm{N}=15, \mathrm{C} 5 \mathrm{aRA}+\mathrm{TP} ; \mathrm{N}$ $=16)$. After transplantation, the skin was closed with wound clips and ampicillin $(12.5 \mathrm{mg} / \mathrm{kg})$ was injected subcutaneously. These mice were sacrificed 42 days after the $\mathrm{SCl}$.

\section{Bioluminescence imaging}


A Xenogen-IVIS spectrum CCD optical macroscopic imaging system (PerkinElmer, USA) was used in vitro and in vivo for bioluminescence imaging (BLI) to confirm the survival of the transplanted hiPSC-NS/PCs, as described previously [23] .

In vitro, the hiPSC-NS/PCs were plated to 8-chamber wells and D-luciferin (1 mg/well) was then added to each well. The luminescent signal was detected immediately using a Xenogen-IVIS spectrum cooled charged-coupled device (CCD) optical macroscopic imaging system (Caliper Life Sciences, USA) ( $N=3$ each group).

In vivo, the mice were injected D-Luciferin ( $300 \mathrm{mg} / \mathrm{kg}$ body weight) intraperitoneally, and placed in a light-tight chamber 15 minutes after injection. The peak of the signal intensity was between 15 and 30 minutes after injection. The integration time was 5 seconds to 2 minutes, depends on the intensity of signals emitted from luciferase-expressing grafted cells. BLI signals were quantified in maximum radiance units (photons/second/centimeter squared/steradian photons $/ \mathrm{sec} / \mathrm{cm}^{3} / \mathrm{sr}$ ) and presented as $\log 10$ values (PBS + TP; $N=15, C 5 a R A+T P ; N=16$ ).

\section{Tissue Immunohistochemistry}

The mice were anesthetized and transcardially perfused with $0.1 \mathrm{M}$ PBS containing 4\% PFA. Their spinal cords were harvested and immersed in $0.1 \mathrm{M}$ PBS containing $4 \%$ PFA at $4{ }^{\circ} \mathrm{C}$ for $24 \mathrm{~h}$. The tissues were transferred into $10 \%$ sucrose for $24 \mathrm{~h}$ followed by $30 \%$ sucrose for $24 \mathrm{~h}$. The sections were embedded in Optimal Cutting Temperature compound (Sakura Finetek Japan, Japan) and immediately frozen by liquid nitrogen and stored at $-30^{\circ} \mathrm{C}$. The tissues were sectioned at $20 \mu \mathrm{m}$ in axial or $16 \mu \mathrm{m}$ sagittal planes using a cryostat (Leica CM3050 S; Leica Microsystems, Germany). The sections were stained with the following primary antibodies overnight at $4{ }^{\circ} \mathrm{C}$; anti-CD88(Rat, 1:400; Biorad, MCA2456), anti-C5R1 (Rabbit, 1:1000; Abcam, ab59390), anti-lba1 (Rabbit, 1:400; WAKO, CDP0133), anti-LY6G (Rat, 1:1000; Novusbio, NBP200441), anti-GFP (Rabbit, 1:2000; MBL), anti-human nuclear antigen (mouse IgG, 1:100; Millipore, MAB4383), anti-human Nestin (Rabbit, 1:200; IBL: 18741), anti-Ki67 (rabbit IgG, 1:200; Leica, NCL-Ki67p), anti-pan-ELAVL (human IgG, 1:1000, a gift from Dr. Robert Darnell; The Rockefeller University, New York, USA)[24], anti-APC (mouse IgG2b, 1:200; Millipore, OP80), and anti-GFAP (Rabbit, 1:2000; Proteintech, AG10423). anti-CD88 and anti-C5R1 antibodies were used as a C5a receptor detection. These sections were incubated with Alexa Fluor 488-, 555-, or 647-conjugated secondary antibodies (Thermo Fisher Scientific, USA), and Hoechst $33258(10 \mu \mathrm{g} / \mathrm{ml}$, Sigma-Aldrich, USA) as a nuclear counterstaining. All images were obtained using a fluorescence microscope (BZ 9000; Keyence Co., Japan) or a confocal laser scanning microscope (LSM 700; Carl Zeiss, Germany). For Quantification of survival rate of grafted cells, anti-GFP (Rabbit, 1:2000; MBL) and Hoechst 33258 (10 $\mu \mathrm{g} / \mathrm{ml}$, Sigma-Aldrich, USA) as a primary antibody and the appropriate secondary antibodies were used. The images were captured at the lesion epicenter and $0.2,0.4,0.6,0.8$, and $1.0 \mathrm{~mm}$ rostral and caudal to the epicenter in axial sections using a fluorescence microscope (BZ 9000; Keyence Co., Japan), and the area of survived grafted cells was assessed by measuring the GFP positive areas on each cross section using ImageJ (https://imagej.nih-.gov/ij/). For quantification of APC-, GFAP-, pan-ELAVL-, Ki67-, Nestin- and OCT4- 
positive cells, five regions within the area $2 \mathrm{~mm}$ rostral and caudal to the lesion epicenter were randomly selected and counted under $\times 63$ magnification.

\section{Locomotor function analysis}

The hindlimb locomotor function analyses were evaluated using the Basso Mouse Scale (BMS) score at 0,1 , and 4 days as well as weekly after $S C l$, up to 35 days [25] (PBS only; $N=20, C 5 a R A$ only; $N=19$, PBS + $T P ; N=15, C 5 a R A+T P ; N=16$ ). Motor coordination was evaluated using a rotating rod apparatus (Rotarod, Muromachikikai Co., Japan), which is composed of a $3 \mathrm{~cm}$ diameter plastic rod rotated at 20 revolutions per min. The mice were tested by monitoring the time spent on the rod (PBS only; $\mathrm{N}=20$, C5aRA only; $N=19, P B S+T P ; N=15, C 5 a R A+T P ; N=16)$. The gait performance of the mice was assessed through treadmill gait analysis (DigiGait system; Mouse Specifics, USA) (PBS only; $N=11, C 5 a R A$ only; $N=$ $11, \mathrm{PBS}+\mathrm{TP} ; \mathrm{N}=8, \mathrm{C} 5 \mathrm{aRA}+\mathrm{TP} ; \mathrm{N}=8$ ).

\section{Statistical analysis}

All data are presented as means \pm SEM. A Mann-Whitney $U$ test was used to identify any significant differences between groups with respect to the results of flowcytometry and immunohistochemistry. Oneway analyses of variance (ANOVA) followed by Tukey-Kramer tests for multiple comparisons were used to detect significant differences in stride length, stance angle, and rotarod score between the four groups. Two-way repeated-measures ANOVA followed by Tukey-Kramer tests were used for the others. For all statistical analyses, the significance level was set at $p<0.05$. Microsoft Excel 2016 and IBM SPSS Statistics (ver. 25) were used for all calculations.

\section{Results}

\section{C5a and C5aR expression in the spinal cord after injury}

To investigate expression of $\mathrm{C} 5 \mathrm{a}$ in the spinal cord, we evaluated the protein levels of C5a before and after injury at different time points. The results revealed that $\mathrm{C} 5$ a protein levels were significantly increased 1 day after injury $(8.16 \pm 0.83 \mathrm{pg} / \mu \mathrm{g}$ protein) and maintained the high amount of protein compared with the one prior to injury $(2.43 \pm 0.45 \mathrm{pg} / \mu \mathrm{g}$ protein $)$ at $4(6.69 \pm 0.99 \mathrm{pg} / \mu \mathrm{g}$ protein $), 7(9.72 \pm$ $0.85 \mathrm{pg} / \mu \mathrm{g}$ protein) and 14 days ( $8.24 \pm 0.98 \mathrm{pg} / \mu \mathrm{g}$ protein) (Fig. $1 \mathrm{~A})$.

Next, we investigated the level and distribution of C5a receptor expression in the injured spinal cord using western blotting and immunohistochemistry. Western blotting showed that the level of C5a receptor expression were upregulated at 1 day after injury, then decreased at days 4 and 7 ( 1 day: 14.02 $\pm 01.54,4$ days: $4.18 \pm 0.85,7$ days: $2.08 \pm 0.16$ ) (Fig. 1B-C). To examine what types of cells expressed the C5a receptor, immunohistochemical analysis was performed for the injured spinal cord. At 1 and 4 days after $\mathrm{SCl}, \mathrm{Iba} 1^{+}$macrophages, activated microglia and some $\mathrm{LY}_{6 \mathrm{G}}{ }^{+}$neutrophils expressed $\mathrm{C} 5$ a receptor (Fig. 1D-E). These results suggest that $\mathrm{C} 5$ a protein was produced immediately after $\mathrm{SCl}$, and that $\mathrm{C} 5 \mathrm{a}$ receptors were expressed in inflammatory cells such as macrophages, activated microglia and neutrophils during the acute phase after SCl. 


\section{Administration of a C5aR antagonist reduced the inflammatory response after SCl}

To investigate the influence of C5aRA on the production of inflammatory cytokines in spinal cord tissue after SCl, C5aRA (PMX205, $1 \mathrm{mg} / \mathrm{kg}$ body weight) were injected into the mice immediately after SCl and the expression of cytokines in spinal cord tissue was evaluated using quantitative RT-PCR. IL-1 $\beta$ and IL- 6 were significantly reduced by the antagonist administration compared to PBS administration at 6 hours (IL-1 $3: 60.9 \pm 11.5$ vs $30.5 \pm 5.2$, IL-6: $1228.8 \pm 380.1$ vs $112.8 \pm 25.0, p<0.05$ ) and 12 hours (IL-1 $\beta: 108.5$ \pm 23.1 vs $36.1 \pm 2.4$, IL-6: $433.3 \pm 102.7$ vs $177.2 \pm 3.6$ p < 0.05) (Fig. $2 A-B$ ). TNFa significantly reduced at 3 hours $(32.6 \pm 6.9$ vs $10.6 \pm 2.2, p<0.05)$ and 6 hours $(21.5 \pm 4.1$ vs $5.5 \pm 1.2, p<0.05)$ after SCl (Fig. $2 C)$. Next, mRNA-Seq analysis was performed to analyze the influence of C5aRA on the gene expression profile in the injured spinal cord. mRNA sequencing revealed that the expression of genes associated with inflammatory cytokines was suppressed by administering C5aRA at 12 hours after SCl (Fig. 2D). With regard to the apoptotic and necroptotic markers, administration of C5aRA also downregulated several apoptotic (Caspase8 and Pidd1) and necroptotic (RIPK3 and MLKL) markers 4 days after injury (Fig. 2E).

To investigate whether $\mathrm{C} 5 \mathrm{aR}$ inhibition blocked infiltration of neutrophils and macrophages after $\mathrm{SCl}$, flow cytometric analysis was performed. The results showed that administration of C5aRA reduced the number of $\mathrm{CD} 45^{+} / \mathrm{LY}_{6 \mathrm{G}}{ }^{+}$neutrophils and $\mathrm{CD} 45^{+} / \mathrm{CD} 11 \mathrm{~b}^{\text {high }}$ macrophages in the spinal cord compared to administration of PBS (Neutrophils: $151 \pm 12$ cells $/ 2 \times 10^{5}$ events vs $270 \pm 25$ cells $/ 2 \times 10^{5}$ events Macrophage: $1198 \pm 111$ cells $/ 2 \times 10^{5}$ events vs $2128 \pm 173$ cells $/ 2 \times 10^{5}$ events, $\left.p<0.05\right)$ (Fig. $2 F-G$ ). These findings indicate that the acute inflammatory response after $\mathrm{SCl}$ occurs through $\mathrm{C} 5 \mathrm{a}$ receptor activation, and inhibition of the C5a-C5aR axis suppressed inflammatory cytokine production and infiltration of inflammatory cells.

C5aR antagonist injection does not affect cell differentiation in vitro.

To investigate the influence of C5aRA on hiPSC-NS/PCs, we evaluated the differentiation profiles and expression of the C5a receptor in these cells. The hiPSC- NS/PCs with or without C5aRA presented similar differentiation patterns; $\beta$ III-tubulin ${ }^{+}$neurons ( $49.38 \pm 3.87 \%$ vs. $\left.44.87 \pm 5.14 \%, p=0.275\right)$, GFAP ${ }^{+}$ astrocytes $(1.01 \pm 1.01 \%$ vs. $2.53 \pm 1.29 \%, p=0.246)$, and $04^{+}$oligodendrocytes $(0 \pm 0 \%$ vs. $0 \pm 0 \%, p=$ 1.00) (Fig. 3A-C), and there were no significant differences in all cell types between the groups (Fig. 3C). In addition, the hiPSC-NS/PCs rarely expressed C5a receptor (Fig. 3D). These findings suggest that C5aR antagonist did not change the differentiation properties of hiPSC-NS/PCs.

\section{Inhibition of C5aR increases the survival rate of grafted NS/PCs}

To examine the effect of C5aRA on the survival rate of grafted cells, we assessed the luminescence of the grafted cells using BLI (Fig. 4A). The BLI analyses demonstrated that the luminescence of the grafted 
cells in the C5aRA + TP group was significantly higher than that of grafted cells in the PBS + TP group at 14 days post-SCl and thereafter (C5aRA + TP vs PBS + TP; day14: $4.86 \pm 0.71 \mathrm{E}+07$ vs $3.24 \pm 0.51 \mathrm{E}+07$, day21: $4.93 \pm 0.94 \mathrm{E}+07$ vs $2.64 \pm 0.51 \mathrm{E}+07$, day $28: 6.85 \pm 0.94 \mathrm{E}+07$ vs $2.39 \pm 0.46 \mathrm{E}+07, \mathrm{p}<0.05)$ (Fig. 4B).

We also evaluated grafted cell survival using immunohistochemistry. In the C5aRA + TP group, GFP ${ }^{+}$area had a tendency to increase compared to PBS + TP group in each axial section (Fig. 4C), and total volume of GFP + areas was significantly larger compared to the PBS + TP group (C5aRA; $0.29 \pm 0.05 \mathrm{~mm}^{3}$, PBS; $0.13 \pm 0.03 \mathrm{~mm}^{3}, p<0.05$ ) (Fig. 4D). These results indicate that inhibition of C5aR improves the survival and proliferation of hiPSC-derived NS/PCs after the transplantation.

\section{Administration of C5aR antagonist does not affect cell differentiation in vivo}

In order to evaluate the neural differentiation and proliferation of the grafted cells in vivo, we performed immunohistochemical analyses using antibodies specific for human nuclear antigen (HNA) and cell type specific markers. Immunohistochemistry revealed that the HNA positive grafted cells in the C5aRA + TP and PBS + TP groups differentiated into pan-ELAVL ${ }^{+}$neurons $(37.0 \pm 3.6 \%$ and $36.8 \pm 3.9 \%, p=0.827)$, GFAP $^{+}$astrocytes $(46.2 \pm 6.0 \%$ and $33.1 \pm 3.2 \% \mathrm{p}=0.127)$, and $\mathrm{APC}^{+}$oligodendrocytes $(8.0 \pm 1.2 \%$ and $11.6 \pm 1.5 \%, p=0.127$ ) (Fig. 5A-B). The differentiation rates of neurons, astrocytes, and oligodendrocytes did not significantly differ between the C5aRA + TP and PBS + TP groups (Fig. 5C). The proportions of Ki $67^{+}$cells $(2.5 \pm 0.7 \%$ vs. $2.7 \pm 0.8 \%, p=0.43)$ and 0 CT $3 / 4^{+}$cells $(0 \pm 0 \%$ vs. $0 \pm 0 \%, p=1.0)$ were not significantly different between the two groups (Fug5C).

\section{C5aR inhibition at the acute phase improved locomotor function}

We assessed hindlimb locomotor function using the BMS score, Rotor-rod test, and treadmill gait analysis with the Digigait system. The average BMS scores of the C5aRA + TP group were significantly higher than those of the PBS group at day $28(3.5 \pm 0.3$ vs. $2.4 \pm 0.2, p<0.05)$ and day $35(3.8 \pm 0.3$ vs. $2.4 \pm 0.2, p<$ 0.05 ) after $\mathrm{SCl}$ (Fig. 6A). In the Rotor-rod test, which was evaluated at day 35 , the running time of mice in the C5aRA + TP group was significantly longer than the time in the other groups (C5aRA + TP:17.5 \pm 4.0sec; PBS + TP: $9.7 \pm 1.3 \mathrm{sec}$; C5aRA: $9.5 \pm 1.2 \mathrm{sec}$; PBS: $7.5 \pm 0.8 \mathrm{sec}, \mathrm{p}<0.05)$ (Fig. 6B). Using the treadmill Digigait system to analyze gait performance, only the mice in the C5aRA + TP groups showed significant improvement in stride length (C5aRA + TP: $4.17 \pm 0.16 \mathrm{~cm}$; PBS + TP: $3.74 \pm 0.16 \mathrm{~cm}$; C5aRA: $3.65 \pm 0.08 \mathrm{~cm}$; PBS: $3.43 \pm 0.13 \mathrm{~cm}, \mathrm{p}<0.05)$ ) or paw angle (C5aRA + TP: $23.5 \pm 3.3^{\circ}$; PBS + TP: $32.8 \pm$ $3.8^{\circ}$ C5aRA: $29.1 \pm 3.7^{\circ}$; PBS: $\left.41.9 \pm 4.5^{\circ}\right)$ compared with the PBS group $(p<0.05)$ (Fig. $\left.6 C-D\right)$.

\section{Discussion}


As shown previously, anti-inflammatory treatment is needed to enable efficient cell transplantation therapy during acute phase because transplanted cell rarely survives in an inflammatory environment in spinal cord during acute phase after $\mathrm{SCl}$, but effective immunosuppressant which increase grafted cell survival has not been found. Therefore, we hypothesized that C5aRA could be a novel immunosuppressant which strongly suppressed inflammatory reaction after $\mathrm{SCl}$ and enables efficient hiPSC-NS/PCs transplantation during acute phase. The present study demonstrates that C5aRA administration after $\mathrm{SCl}$ significantly reduces upregulation of IL-1ß, IL- 6 and $\mathrm{TNFa}$, as well as the infiltration of neutrophils and macrophages. C5aRA also downregulated the expression of inflammatory cytokines and apoptosis markers, which was demonstrated by RNA sequence analysis. The combined therapy of hiPSC-NS/PCs transplantation and C5aRA decreased the grafted cell death compared to cell transplantation monotherapy. Consequently, this combined therapy significantly improved locomotor function after $\mathrm{SCl}$. Our findings show that $\mathrm{C5aRA}$ could be a promising medication to enhance the efficacy of hiPSC-NS/PCs when transplanted during the acute phase of SCI.

It is well known that inflammatory reactions play a critical role in the exacerbation of secondary damage in the SCI microenvironment $[6,8,10,26]$. In particular, IL-1 $\beta$ and TNFa contribute to upregulation of several inflammatory mediators, recruiting neutrophils and macrophages, and resulting in the apoptosis of neurons and oligodendrocytes after SCI [27-31]. IL-6 also promotes cytotoxic macrophage infiltration into the lesion and increases secondary damage $[32,33]$. Neutrophil and macrophage infiltration into the lesion area is a detrimental factor for resident cell survival and functional recovery after $\mathrm{SCl}$ [34-37]. A previous study showed that these inflammatory cytokines and cells were regulated by the complement C5a-C5aR axis, and that inhibition of these factors decreased resident cell death, thus improving functional restoration after $\mathrm{SCl}$ [17]. In the present study, we demonstrated that administration of $\mathrm{C5aRA}$ reduced secretion of various cytokines, infiltration of inflammatory cells, and apoptosis of resident cells in the spinal cord, suggesting that the C5aRA comprehensively suppressed main factors which contribute to secondary damage after $\mathrm{SCl}$. Therefore, the intervention using C5aRA could prevent the expansion of secondary damage and create a hospitable environment for cell survival after transplantation in SCl.

Previous studies have revealed that the acute inflammatory reaction after CNS injury contributes to rejection of grafted cells in spinal cord tissue [38-40]. To address this challenge, several researchers have tried to improve cell engraftment by inhibiting acute inflammatory factors, but few studies have reported successful improvement in cell survival after SCl. For example, depletion of neutrophils was found to decrease the astrogliosis of the transplanted cells, but did not change the survival rate [41]. A reduction in macrophages also failed to favorably affect cell engraftment [37]. It is inferred from those results that the blockade of a single inflammatory factor cannot decrease grafted cell death. Therefore, a strong immunosuppressant capable of blocking several inflammatory reactions after $\mathrm{SCl}$ is indispensable for the improvement of cell survival. C5aRA was an efficacious drug against rejection of hiPSC-NS/PCs transplantation because this medication was able to suppress multiple inflammatory cells, and our results demonstrated amelioration of the cell survival rate. We can deduce from this result that C5aRA is more effective for improving the efficacy of cell transplantation into the injured spinal cord than other 
immunosuppressants, because the C5a-C5aR axis regulates several inflammatory reactions in the acute phase after $\mathrm{SCl}[12]$.

Our results demonstrated that, compared to NS/PC transplantation only, cell engraftment with C5aRA administration decreased cell death and maintained the number of cells, which contributed to functional restoration after $\mathrm{SCl}$. In other words, the intensive inflammatory reaction during the acute phase of $\mathrm{SCl}$ did not allow transplanted cells to survive sufficiently and exert their efficacy when C5aRA was not used. Although the in vivo differentiation profiles were comparable between groups with or without the C5aRA (Fig. 5), our results indicate that it is necessary to secure a certain number of survived transplanted cell for the differentiated cells to play functional roles. By using C5aRA, it is inferred that more NS/PCs differentiated into axons to construct functional circuits, or differentiated into oligodendrocytes for remyelination, and these mechanisms led to functional recovery [2, 42, 43]. If cell transplantation is possible in the acute phase of injury, earlier interventions could become feasible and bring the benefits of regenerative medicine to the $\mathrm{SCl}$ field.

For the transplantation studies using human-derived cells, immunodeficient animals were employed to avoid rejection of the grafted cells. For example, NOD-SCID mice which generally used in transplantation experiment lacked lymphocytes and impaired innate immune system such as neutrophils, macrophage and complement[23, 43-46]. However, NOD-SCID mice are not suitable for our current study because normal activation of the complement system is necessary to evaluate the effect of C5aRA. Immunocompetent mice are also not appropriate for the present study owing to lymphocytes, which strongly reject xenograft $[40,47]$. In this study, we selected SCID-Beige mice, which lack lymphocytes but maintain a functional complement system. We demonstrated that the complement system was activated normally after SCI in SCID-Beige mice, and we could perform evaluating the influence of C5aRA on the grafted cells and locomotor function recovery. Thus, the SCID-Beige mouse was a reasonable tool to evaluate the impact of complements on the transplanted cells in SCl.

Importantly, as it is known that T cells and NK cells can express C5a receptor[48, 49], this study using SCID-Beige mice might be insufficient to accurately evaluate the effect of C5aRA against cell transplantation after $\mathrm{SCl}$. Therefore, further study using immunocompetent mice with lymphocyte depressants are necessary to enhance our understanding.

In this study, we showed the efficacy of the combined therapy C5aRA and hiPSC-NS/PCs transplantation for SCl in SCID-Beige mice. However, in order to apply this treatment in a clinical setting, it is necessary to perform further studies using C5aRA, which has already been clinically applied, instead of PMX205 that is not approved for marketing [16]. For example, CCX168 has completed phase $\nabla$ trials [50] and is one of the most advanced C5aRA in clinical development. However, because CCX168 is effective only in human C5aR, further studies using human C5a knock-in mice are necessary.

\section{Conclusion}


The present study demonstrates that the administration of C5aRA suppresses the inflammatory response during the acute phase of SCl. This beneficial effect led to improved transplanted hiPSC-NS/PCs survival rates as well as the enhancement of motor functional restoration. These findings suggest that administration of C5aRA makes it possible to transplant hiPSC-NS/PCs during the acute phase of SCI. This work opens a potentially novel strategy wherein the transplantation of neural stem cells could be combined with early decompressive surgery as a one stage treatment for severe SCl.

\section{Abbreviations}

\section{BLI}

bioluminescence imaging; BMS:Basso-Beattie-Bresnahan; CCD:Charge Coupled Device; C5aRA:C5a receptor antagonist; $C D$ :cluster of differentiation; EB:embryoid body; ECL:Enhanced chemiluminescence; ELISA:Enzyme-linked immunosorbent assay; GFAP:Glial fibrillary acidic protein; HRP:Horseradish peroxidase; IL:Interleukin; IVIS:In vivo imaging system; hiPSC-derived NS/PCs:human induced pluripotent stem cell derived neural stem/progenitor cells; PBS:Phosphate-buffered saline; qPCR:Quantitative polymerase chain reaction; RHI:Rump-height Index; RIP3:Receptor-interacting serine-threonine kinase 3; RNA:Ribonucleic acid; SCl:Spinal cord injury; SDS-PAGE:Sodium dodecyl sulfate Polyacrylamide gel electrophoresis; SEM:standard error of the mean; TNF:Tumor necrosis factor; TP:Transplantation

\section{Declarations}

\section{Acknowledgments}

We appreciate the assistance of O. Tsuji, M. Shinozaki, T. Kondo, T. lida, T. Okubo, S. Ito, K. Kojima, Y. Tanimoto, Y. Hoshino, Y. Kamata, K. Kajikawa, K. Ago, T. Kitagawa, and M. Kawai who are all members of the spinal cord research team in the Department of Orthopaedic Surgery and Physiology, Keio University School of Medicine, Tokyo, Japan. We also thank K. Yasutake, T. Harada, and M. Akizawa for their assistance with the experiments and animal care. Furthermore, we thank T. Worden for his assistance in proofreading.

\section{Funding}

This study was supported by JSPS KAKENHI (Grant Number $17 \mathrm{H} 04318$ to N.N.), a medical research grant on traffic accidents from The General Insurance Association of Japan, and AO Spine Japan (AOSJP(R)2017-14).

\section{Availability of data and materials}

The datasets used and/or analyzed during the current study are available from the corresponding author on reasonable request.

\section{Authors' contributions}


R.S., N.N., K.M. M.F., M.N. and H.O. designed the project. R.S. performed most of the experiments and acquired and analyzed the data. R.S. and N.N. wrote the manuscript. Technical assistance and experimental support were provided by N.N., S.I., K.K., S.N., J.K., and M.M. Supervision of the overall project and preparation of the final manuscript were performed by N.N., S.N., K.M., J.K., M.F., M.M., M.N. and H.O.

\section{Ethics approval}

All animal experiments were performed in accordance with guidelines fromthe Keio University Ethics Committee(Assurance No. 13020).

\section{Consent for publication}

Not applicable.

\section{Competing interests}

The authors declare that they have no competing interestsrelated to the present study.

\section{Author details}

Reo Shibata1,2(leos0519@icloud.com), Narihito Nagoshi¹(nagoshi@keio.jp), Keita Kajikawa1,2(keita.kajiko@gmail.com),Shuhei Ito ${ }^{1}$ (shuheiazb@gmail.com), Mohamad Khazaei ${ }^{3}$ (khazaei.mr@gmail.com), Satoshi Nori¹(satoshi.nori@gmail.com),Jun Kohyama²(jkohyama@a7.keio.jp), Michael G. Fehlings³(Michael.Fehlings@uhn.ca), Morio Matsumoto(morio@a5.keio.jp), Masaya Nakamura¹(masa@keio.jp), Hideyuki Okano²(hidokano@a2.keio.jp).

${ }^{1}$ Department of Orthopaedic Surgery, Keio University School of Medicine, Tokyo, Japan. ${ }^{2}$ Department ofPhysiology, Keio University School of Medicine, Tokyo, Japan. ${ }^{3}$ Division of Genetics and Development, Krembil Research Institute, University Health Network, Toronto, Ontario, Canada.

\section{References}

1. Ahuja CS, Wilson JR, Nori S, Kotter MRN, Druschel C, Curt A, Fehlings MG. Traumatic spinal cord injury. Nat Rev Dis Primers. 2017;3:17018.

2. Nori S, Okada Y, Yasuda A, Tsuji O, Takahashi Y, Kobayashi Y, Fujiyoshi K, Koike M, Uchiyama Y, Ikeda $E$, et al. Grafted human-induced pluripotent stem-cell-derived neurospheres promote motor functional recovery after spinal cord injury in mice. Proc Natl Acad Sci U S A. 2011;108:16825-30.

3. Kobayashi Y, Okada Y, Itakura G, Iwai H, Nishimura S, Yasuda A, Nori S, Hikishima K, Konomi T, Fujiyoshi K, et al. Pre-evaluated safe human iPSC-derived neural stem cells promote functional 
recovery after spinal cord injury in common marmoset without tumorigenicity. PLoS One. 2012;7:e52787.

4. Khazaei M, Ahuja CS, Nakashima H, Nagoshi N, Li L, Wang J, Chio J, Badner A, Seligman D, Ichise A, et al: GDNF rescues the fate of neural progenitor grafts by attenuating Notch signals in the injured spinal cord in rodents. Sci Transl Med 2020, 12.

5. Tsuji O, Sugai K, Yamaguchi R, Tashiro S, Nagoshi N, Kohyama J, lida T, Ohkubo T, Itakura G, Isoda $M$, et al. Concise Review: Laying the Groundwork for a First-In-Human Study of an Induced Pluripotent Stem Cell-Based Intervention for Spinal Cord Injury. Stem Cells. 2019;37:6-13.

6. Okano H. Stem cell biology of the central nervous system. J Neurosci Res. 2002;69:698-707.

7. Ogawa Y, Sawamoto K, Miyata T, Miyao S, Watanabe M, Nakamura M, Bregman BS, Koike M, Uchiyama $\mathrm{Y}$, Toyama $\mathrm{Y}$, Okano $\mathrm{H}$. Transplantation of in vitro-expanded fetal neural progenitor cells results in neurogenesis and functional recovery after spinal cord contusion injury in adult rats. $\mathrm{J}$ Neurosci Res. 2002;69:925-33.

8. Nakamura M, Houghtling RA, MacArthur L, Bayer BM, Bregman BS. Differences in cytokine gene expression profile between acute and secondary injury in adult rat spinal cord. Exp Neurol. 2003;184:313-25.

9. Hausmann ON. Post-traumatic inflammation following spinal cord injury. Spinal Cord. 2003;41:36978.

10. Anderson AJ, Robert S, Huang W, Young W, Cotman CW. Activation of complement pathways after contusion-induced spinal cord injury. J Neurotrauma. 2004;21:1831-46.

11. Alexander JJ, Anderson AJ, Barnum SR, Stevens B, Tenner AJ. The complement cascade: Yin-Yang in neuroinflammation-neuro-protection and -degeneration. J Neurochem. 2008;107:1169-87.

12. Peterson SL, Anderson AJ. Complement and spinal cord injury: traditional and non-traditional aspects of complement cascade function in the injured spinal cord microenvironment. Exp Neurol. 2014;258:35-47.

13. Roselli F, Karasu E, Volpe C, Huber-Lang M. Medusa's Head: The Complement System in Traumatic Brain and Spinal Cord Injury. J Neurotrauma. 2018;35:226-40.

14. Chenoweth DE, Hugli TE. Demonstration of specific C5a receptor on intact human polymorphonuclear leukocytes. Proc Natl Acad Sci U S A. 1978;75:3943-7.

15. Woodruff TM, Nandakumar KS, Tedesco F. Inhibiting the C5-C5a receptor axis. Mol Immunol. 2011;48:1631-42.

16. Kumar V, Lee JD, Clark RJ, Noakes PG, Taylor SM, Woodruff TM. Preclinical Pharmacokinetics of Complement C5a Receptor Antagonists PMX53 and PMX205 in Mice. ACS Omega. 2020;5:2345-54.

17. Brennan FH, Gordon R, Lao HW, Biggins PJ, Taylor SM, Franklin RJ, Woodruff TM, Ruitenberg MJ. The Complement Receptor C5aR Controls Acute Inflammation and Astrogliosis following Spinal Cord Injury. J Neurosci. 2015;35:6517-31. 
18. Scheff SW, Rabchevsky AG, Fugaccia I, Main JA, Lumpp JE Jr. Experimental modeling of spinal cord injury: characterization of a force-defined injury device. J Neurotrauma. 2003;20:179-93.

19. Saiwai H, Ohkawa Y, Yamada H, Kumamaru H, Harada A, Okano H, Yokomizo T, Iwamoto Y, Okada S. The LTB4-BLT1 axis mediates neutrophil infiltration and secondary injury in experimental spinal cord injury. Am J Pathol. 2010;176:2352-66.

20. Okada Y, Matsumoto A, Shimazaki T, Enoki R, Koizumi A, Ishii S, Itoyama Y, Sobue G, Okano H. Spatiotemporal recapitulation of central nervous system development by murine embryonic stem cell-derived neural stem/progenitor cells. Stem Cells. 2008;26:3086-98.

21. Hara-Miyauchi C, Tsuji O, Hanyu A, Okada S, Yasuda A, Fukano T, Akazawa C, Nakamura M, Imamura T, Matsuzaki Y, et al. Bioluminescent system for dynamic imaging of cell and animal behavior. Biochem Biophys Res Commun. 2012;419:188-93.

22. Nagai T, Ibata K, Park ES, Kubota M, Mikoshiba K, Miyawaki A. A variant of yellow fluorescent protein with fast and efficient maturation for cell-biological applications. Nat Biotechnol. 2002;20:87-90.

23. Kojima K, Miyoshi H, Nagoshi N, Kohyama J, Itakura G, Kawabata S, Ozaki M, lida T, Sugai K, Ito S, et al. Selective Ablation of Tumorigenic Cells Following Human Induced Pluripotent Stem Cell-Derived Neural Stem/Progenitor Cell Transplantation in Spinal Cord Injury. Stem Cells Transl Med. 2019;8:260-70.

24. Okano HJ, Darnell RB. A hierarchy of Hu RNA binding proteins in developing and adult neurons. J Neurosci. 1997;17:3024-37.

25. Basso DM, Fisher LC, Anderson AJ, Jakeman LB, McTigue DM, Popovich PG. Basso Mouse Scale for locomotion detects differences in recovery after spinal cord injury in five common mouse strains. $J$ Neurotrauma. 2006;23:635-59.

26. Beck KD, Nguyen HX, Galvan MD, Salazar DL, Woodruff TM, Anderson AJ. Quantitative analysis of cellular inflammation after traumatic spinal cord injury: evidence for a multiphasic inflammatory response in the acute to chronic environment. Brain. 2010;133:433-47.

27. Nesic O, Xu GY, McAdoo D, High KW, Hulsebosch C, Perez-Pol R. IL-1 receptor antagonist prevents apoptosis and caspase-3 activation after spinal cord injury. J Neurotrauma. 2001;18:947-56.

28. Sato A, Ohtaki H, Tsumuraya T, Song D, Ohara K, Asano M, Iwakura Y, Atsumi T, Shioda S. Interleukin1 participates in the classical and alternative activation of microglia/macrophages after spinal cord injury. J Neuroinflammation. 2012;9:65.

29. Boato F, Rosenberger K, Nelissen S, Geboes L, Peters EM, Nitsch R, Hendrix S. Absence of IL-1ß positively affects neurological outcome, lesion development and axonal plasticity after spinal cord injury. J Neuroinflammation. 2013;10:6.

30. Genovese T, Mazzon E, Crisafulli C, Di Paola R, Muia C, Esposito E, Bramanti P, Cuzzocrea S. TNFalpha blockage in a mouse model of SCl: evidence for improved outcome. Shock. 2008;29:32-41.

31. Wang L, Wei FX, Cen JS, Ping SN, Li ZQ, Chen NN, Cui SB, Wan Y, Liu SY. Early administration of tumor necrosis factor-alpha antagonist promotes survival of transplanted neural stem cells and axon myelination after spinal cord injury in rats. Brain Res. 2014;1575:87-100. 
32. Mukaino M, Nakamura M, Yamada O, Okada S, Morikawa S, Renault-Mihara F, Iwanami A, Ikegami T, Ohsugi Y, Tsuji 0, et al. Anti-IL-6-receptor antibody promotes repair of spinal cord injury by inducing microglia-dominant inflammation. Exp Neurol. 2010;224:403-14.

33. Nakamura M, Okada S, Toyama Y, Okano H. Role of IL-6 in spinal cord injury in a mouse model. Clin Rev Allergy Immunol. 2005;28:197-204.

34. Chatham WW, Swaim R, Frohsin H Jr, Heck LW, Miller EJ, Blackburn WD. Jr.: Degradation of human articular cartilage by neutrophils in synovial fluid. Arthritis Rheum. 1993;36:51-8.

35. Nguyen HX, Galvan MD, Anderson AJ. Characterization of early and terminal complement proteins associated with polymorphonuclear leukocytes in vitro and in vivo after spinal cord injury. $J$ Neuroinflammation. 2008;5:26.

36. Popovich PG, Guan Z, Wei P, Huitinga I, van Rooijen N, Stokes BT. Depletion of hematogenous macrophages promotes partial hindlimb recovery and neuroanatomical repair after experimental spinal cord injury. Exp Neurol. 1999;158:351-65.

37. Lee YS, Funk LH, Lee JK, Bunge MB. Macrophage depletion and Schwann cell transplantation reduce cyst size after rat contusive spinal cord injury. Neural Regen Res. 2018;13:684-91.

38. Li P, Tessler A, Han SS, Fischer I, Rao MS, Selzer ME. Fate of immortalized human neuronal progenitor cells transplanted in rat spinal cord. Arch Neurol. 2005;62:223-9.

39. Molcanyi M, Riess P, Bentz K, Maegele M, Hescheler J, Schafke B, Trapp T, Neugebauer E, Klug N, Schafer U. Trauma-associated inflammatory response impairs embryonic stem cell survival and integration after implantation into injured rat brain. J Neurotrauma. 2007;24:625-37.

40. Anderson AJ, Haus DL, Hooshmand MJ, Perez H, Sontag CJ, Cummings BJ. Achieving stable human stem cell engraftment and survival in the CNS: is the future of regenerative medicine immunodeficient? Regen Med. 2011;6:367-406.

41. Nguyen HX, Hooshmand MJ, Saiwai H, Maddox J, Salehi A, Lakatos A, Nishi RA, Salazar D, Uchida N, Anderson AJ. Systemic Neutrophil Depletion Modulates the Migration and Fate of Transplanted Human Neural Stem Cells to Rescue Functional Repair. J Neurosci. 2017;37:9269-87.

42. Nagoshi N, Okano H. iPSC-derived neural precursor cells: potential for cell transplantation therapy in spinal cord injury. Cell Mol Life Sci. 2018;75:989-1000.

43. Cummings BJ, Uchida N, Tamaki SJ, Salazar DL, Hooshmand M, Summers R, Gage FH, Anderson AJ. Human neural stem cells differentiate and promote locomotor recovery in spinal cord-injured mice. Proc Natl Acad Sci U S A. 2005;102:14069-74.

44. Shultz LD, Schweitzer PA, Christianson SW, Gott B, Schweitzer IB, Tennent B, McKenna S, Mobraaten L, Rajan TV, Greiner DL, et al. Multiple defects in innate and adaptive immunologic function in NOD/LtSz-scid mice. J Immunol. 1995;154:180-91.

45. Gerling IC, Serreze DV, Christianson SW, Leiter EH. Intrathymic islet cell transplantation reduces betacell autoimmunity and prevents diabetes in NOD/Lt mice. Diabetes. 1992;41:1672-6.

46. Luchetti S, Beck KD, Galvan MD, Silva R, Cummings BJ, Anderson AJ. Comparison of immunopathology and locomotor recovery in C57BL/6, BUB/BnJ, and NOD-SCID mice after 
contusion spinal cord injury. J Neurotrauma. 2010;27:411-21.

47. Itakura G, Kobayashi Y, Nishimura S, Iwai H, Takano M, Iwanami A, Toyama Y, Okano H, Nakamura M. Controlling immune rejection is a fail-safe system against potential tumorigenicity after human iPSC-derived neural stem cell transplantation. PLoS One. 2015;10:e0116413.

48. Fusakio ME, Mohammed JP, Laumonnier Y, Hoebe K, Kohl J, Mattner J. C5a regulates NKT and NK cell functions in sepsis. J Immunol. 2011;187:5805-12.

49. Lalli PN, Strainic MG, Yang M, Lin F, Medof ME, Heeger PS. Locally produced C5a binds to T cellexpressed $\mathrm{C} 5 \mathrm{aR}$ to enhance effector T-cell expansion by limiting antigen-induced apoptosis. Blood. 2008;112:1759-66.

50. Merkel PA, Jayne DR, Wang C, Hillson J, Bekker P. Evaluation of the Safety and Efficacy of Avacopan, a C5a Receptor Inhibitor, in Patients With Antineutrophil Cytoplasmic Antibody-Associated Vasculitis Treated Concomitantly With Rituximab or Cyclophosphamide/Azathioprine: Protocol for a Randomized, Double-Blind, Active-Controlled, Phase 3 Trial. JMIR Res Protoc. 2020;9:e16664.

\section{Figures}


A

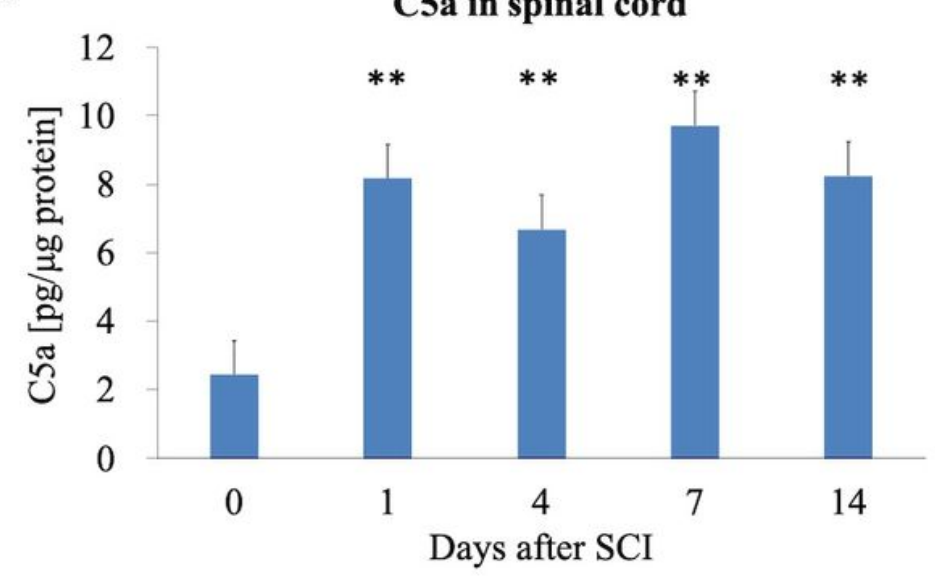

B

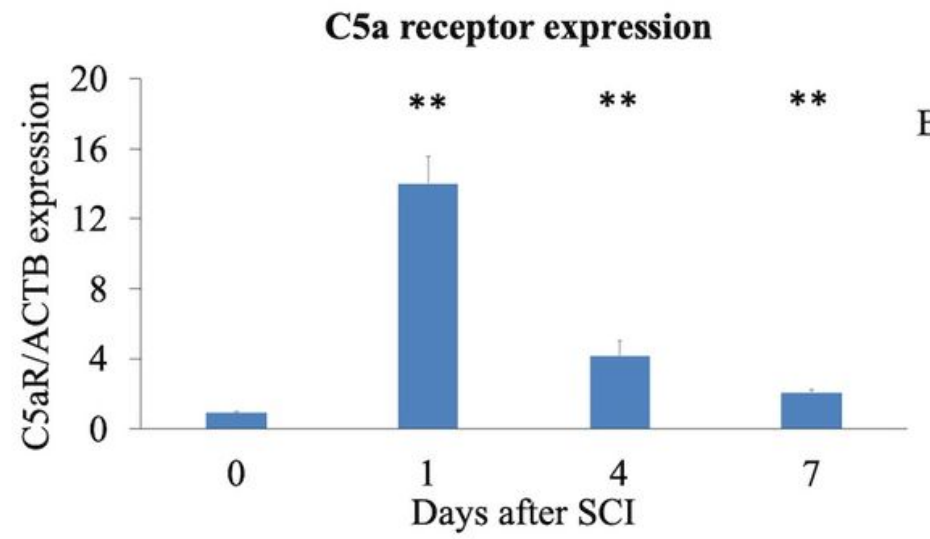

$\mathrm{C}$ Days after SCI

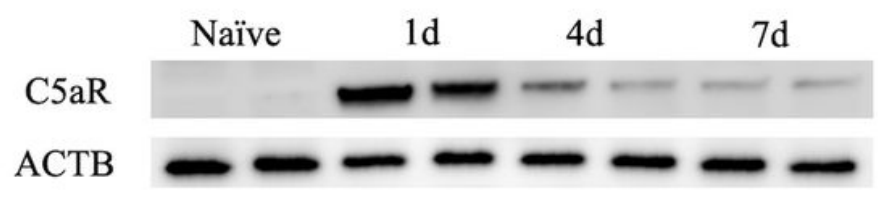

$\mathrm{D}$ 1 day after SCI

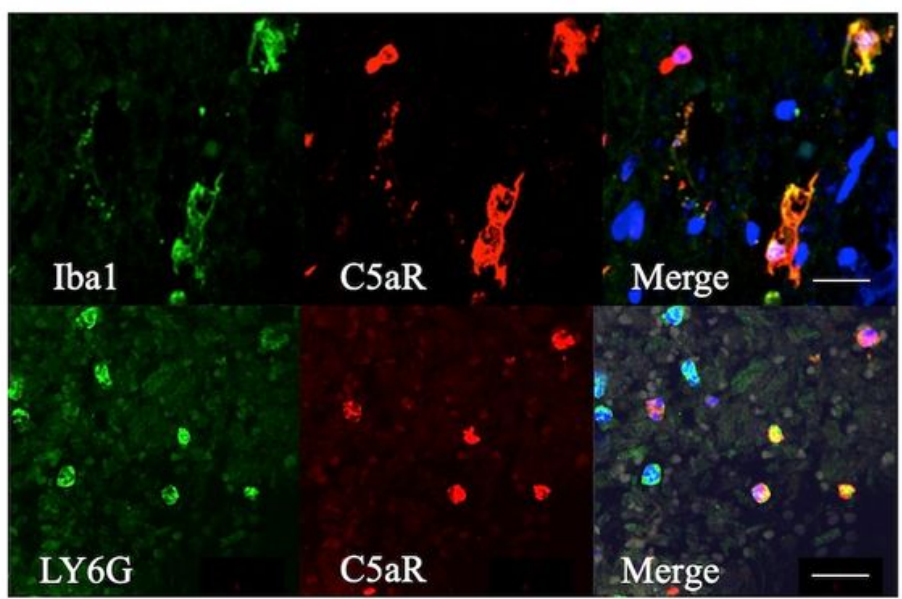

E

4 days after SCI

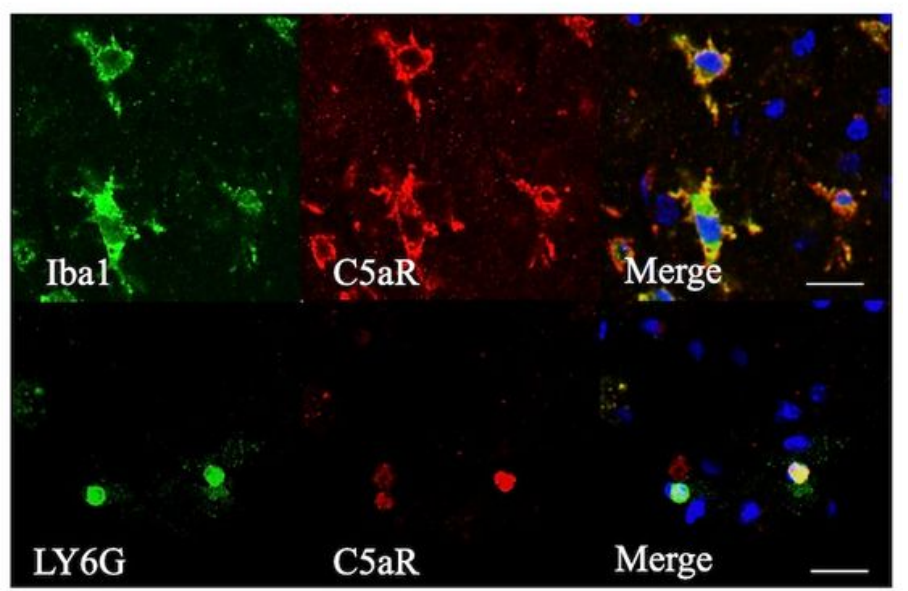

\section{Figure 1}

Determination of C5a production and C5a receptor expression after spinal cord injury A: ELISA analysis of C5a production at $0,1,4,7$, and 14 days after spinal cord injury. **; $p<0.05 \mathrm{~B}$ : Western blot analysis of C5a receptor expression following spinal cord injury at 0, 1, 4, and $7 \mathrm{~d}$. **; p<0.05 C: Representative Western blots demonstrating C5aR expression at 0, 1, 4, $7 \mathrm{~d}$ after SCI. D-E: Representative images of sagittal sections stained for Iba1, LY6G and C5aR at 1 and $4 \mathrm{~d}$ after SCI. Scale bars;20 $20 \mathrm{~m}$. 
A

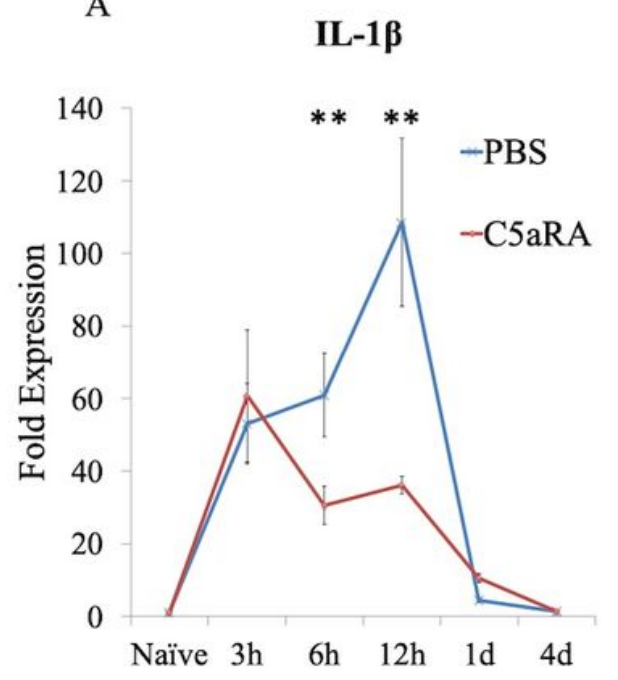

Time after SCI
B

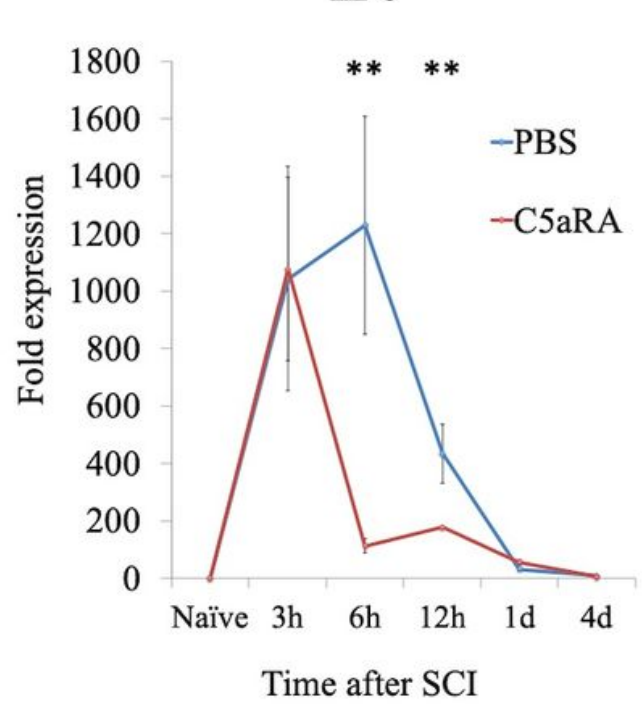

C

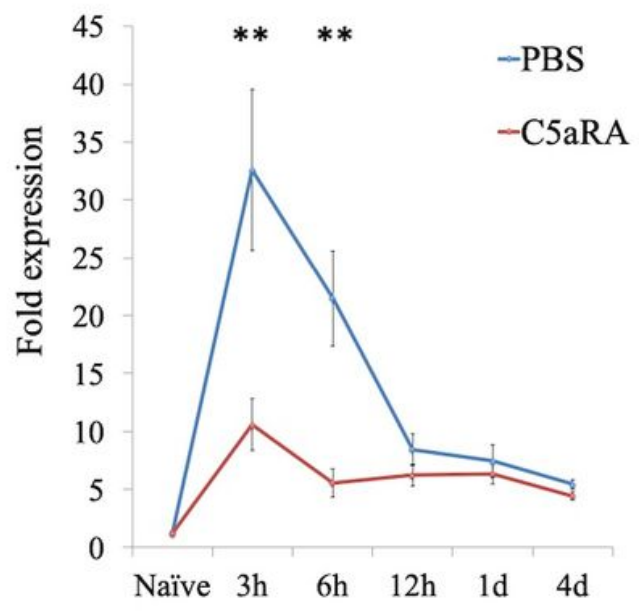

Time after SCI
D

Inflammatory cytokines

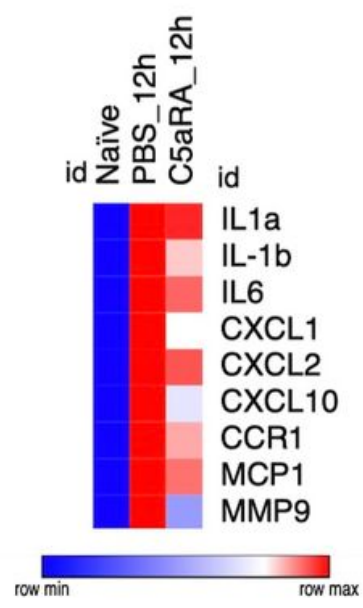

E Apoptotic and Necroptotic Markers

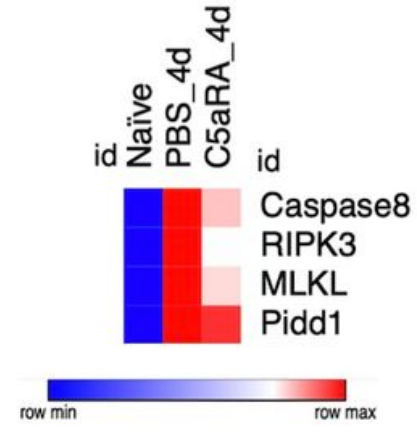

F

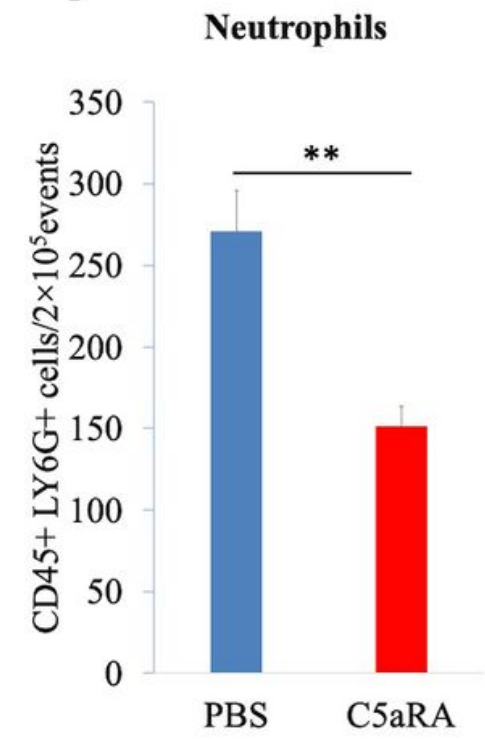

G

Macrophages

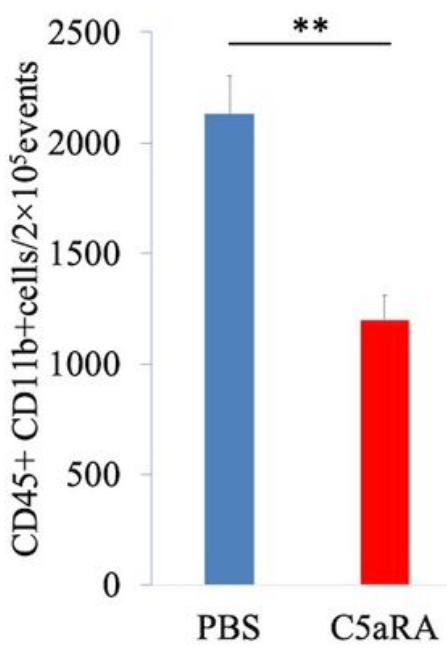

Figure 2

Inflammatory reaction after spinal cord injury with C5aR antagonist. A-C: Inflammatory cytokine (IL-1D, IL6, TNFa) activation at 3h, 6h, 12h, 1d, and 4d after SCI by RT-PCR. **; p<0.05 D: Analysis of inflammatory cytokines at $4 d$ after SCI by RNA sequencing. Heat map of expression profiles for the 9 significant genes involved in inflammation as assessed by RNA-sequencing. E: Analysis of apoptotic necroptotic markers at $4 \mathrm{~d}$ after SCl by RNA sequences. Heat map of expression profiles for the 4 significant genesinvolved in apoptotic and necroptotic markers as assessed by RNA-sequencing. F-G: Analysis of neutrophils and macrophages at $4 d$ after SCl using flow cytometry. **; $p<0.05$ 
A

PBS group

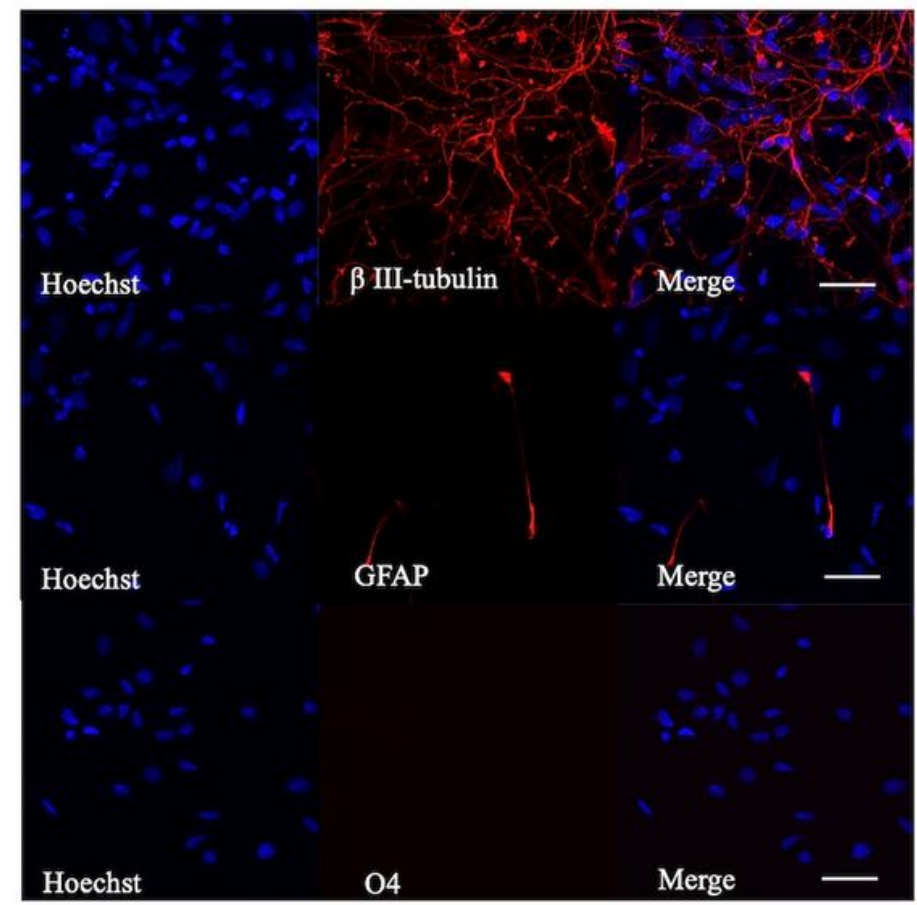

C

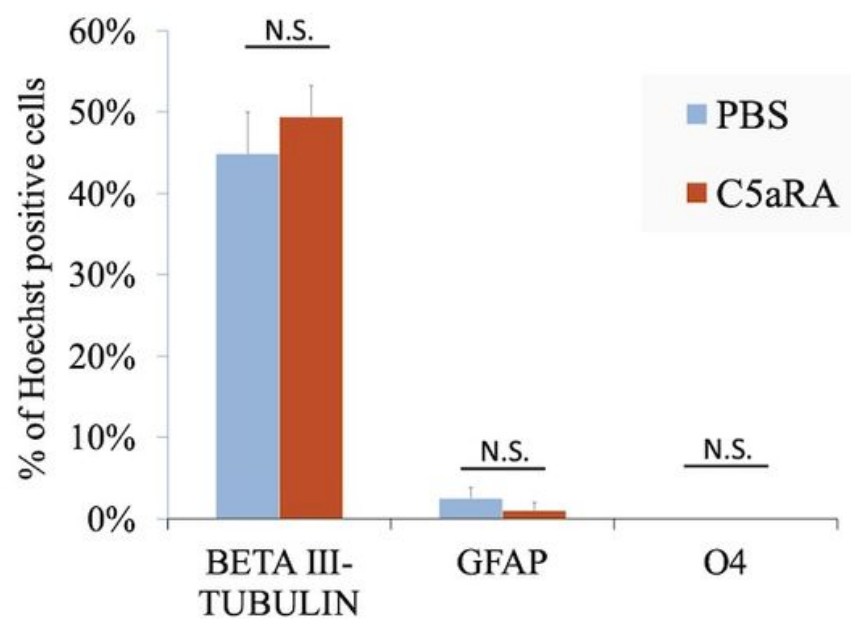

B

C5aRA group

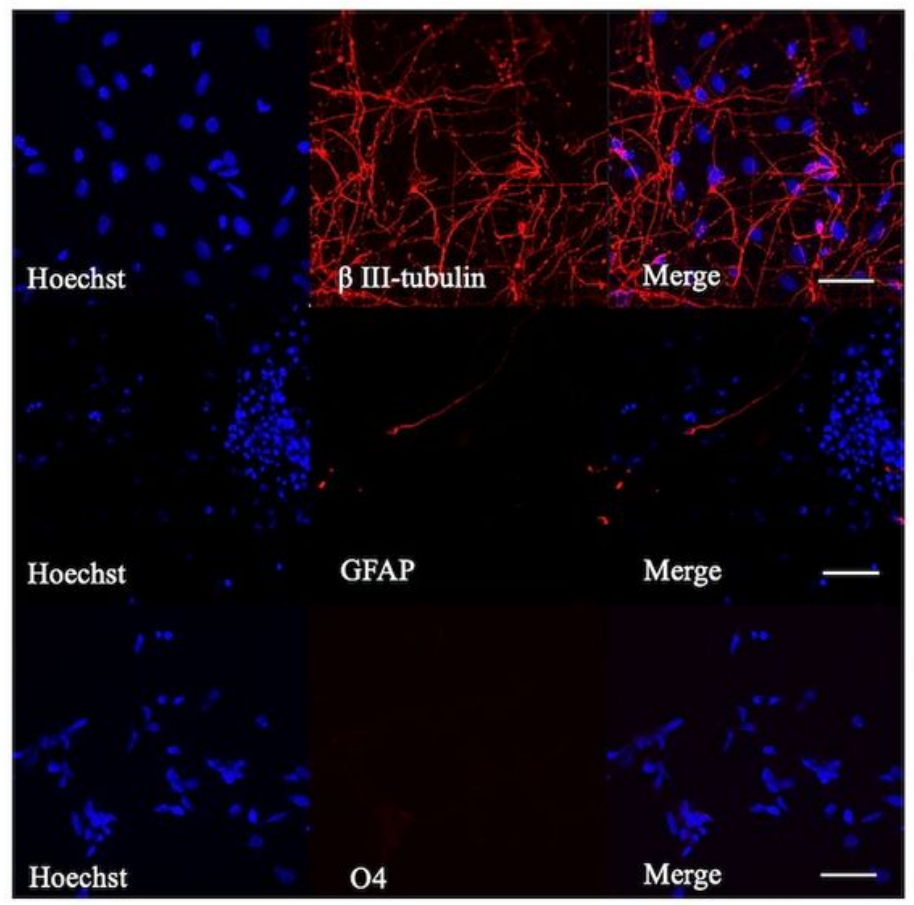

D

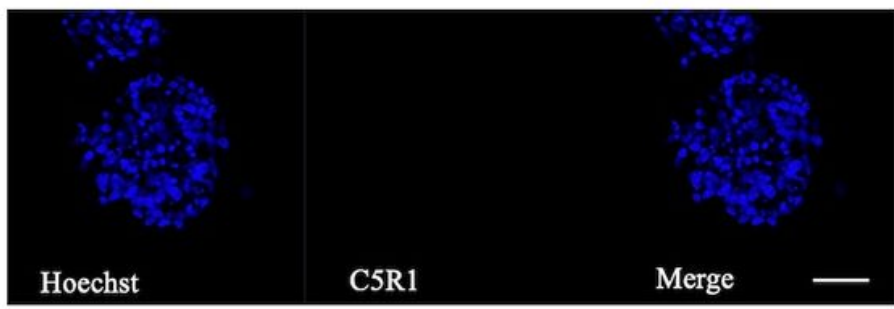

\section{Figure 3}

hiPSC-NS/PCs differentiation and proliferation in vitro. A-B: Representative images of hiPSC-NS/PCs

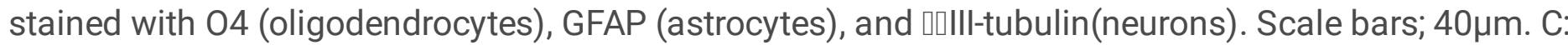
Percentage of cell-type-specific marker positive cells among Hoechst+ cells. NS: Not Significant D: Representative images of C5a receptor expression of hiPSC-NS/PCs in vitro. Scale bars; $40 \mu \mathrm{m}$. 
A

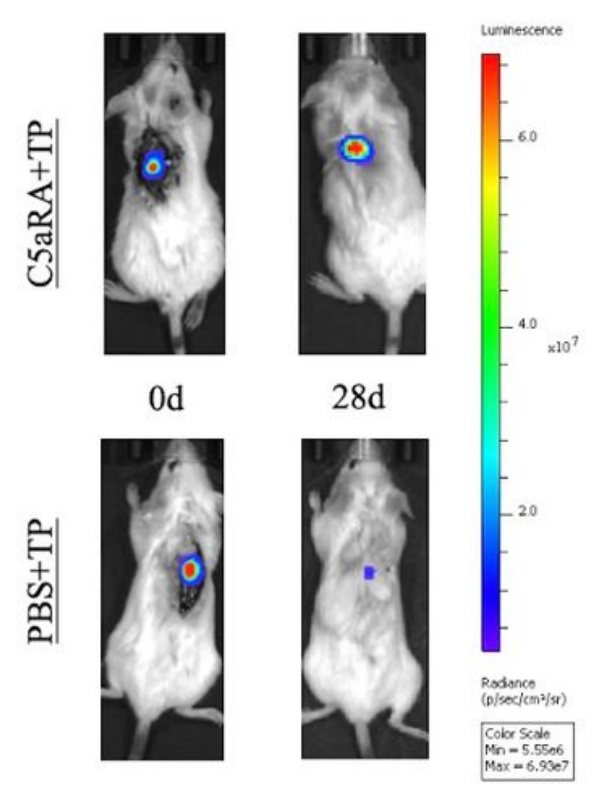

B

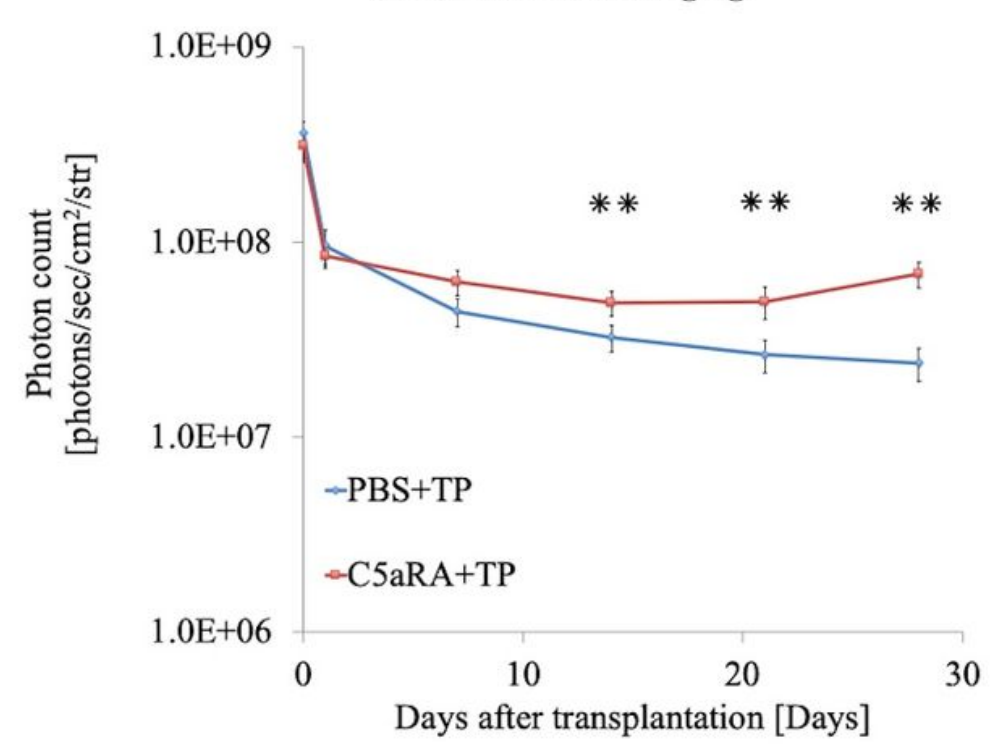

C

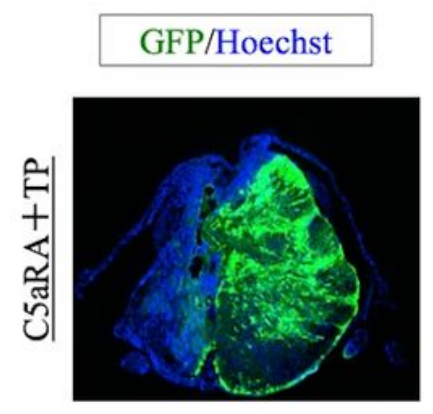

Epicenter

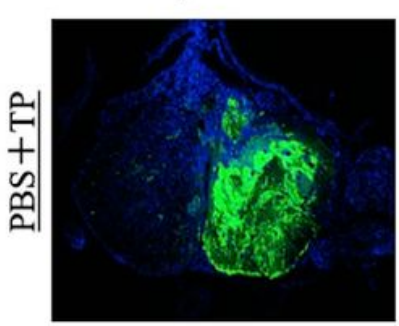

D

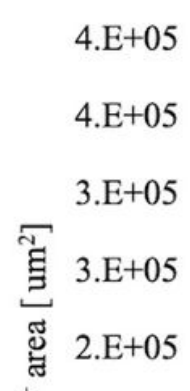

党

$2 . \mathrm{E}+05$

$1 . \mathrm{E}+05$

5.E+04

0. $\mathrm{E}+00$

$\mathrm{GFP}^{+}$area

E

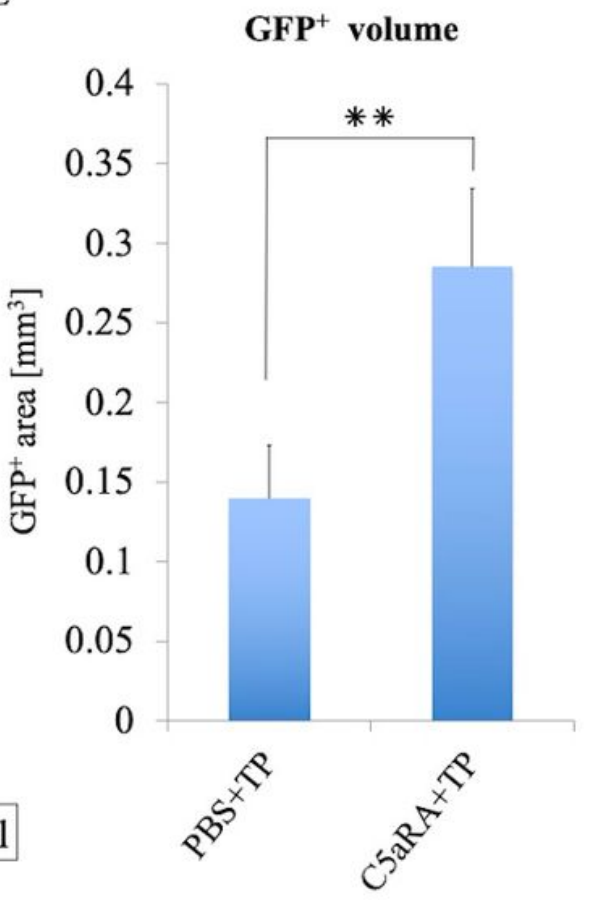

Figure 4

Survival rate of the transplanted cells. A-B: Representative in vivo BLI of PBS+TP and C5aRA+TP group at Od and 28d after transplantation. **; p<0.05 B: Quantification of photon count in both PBS+TP and C5aRA+TP groups. C: Representative images of GFP+ area at epicenter of the lesion. D-E: Quantification of GFP+ area and volume. **; $p<0.05$ 


\section{A}

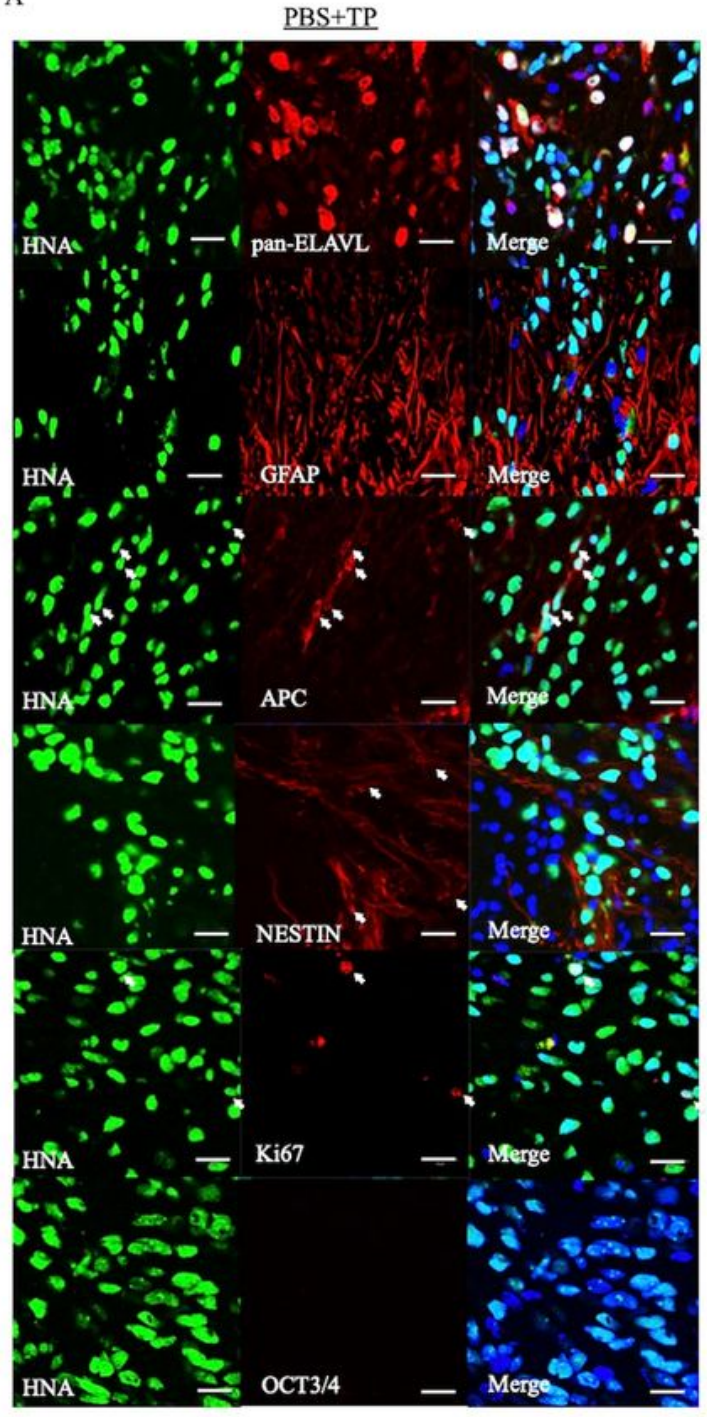

$\mathrm{C}$
B

\section{C5aRA+TP}

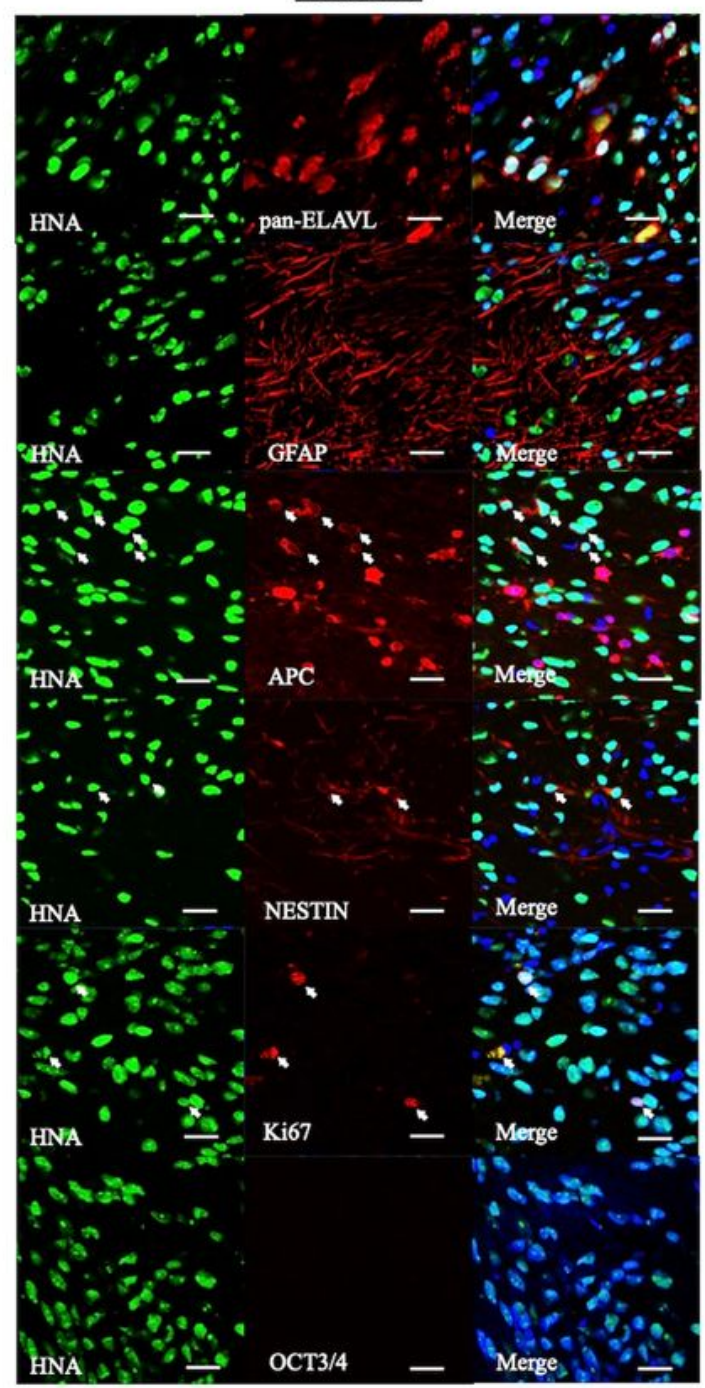

HNA

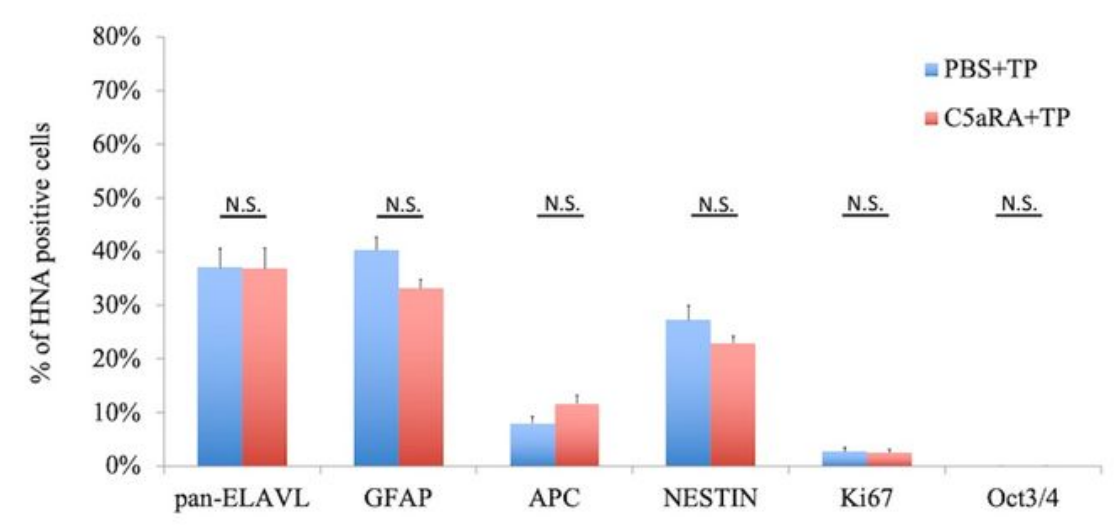

\section{Figure 5}

Transplanted hiPS-NS/PCs differentiation and proliferation. A-B: Representative images of HNA+ transplanted cells labeled with APC (oligodendrocytes), GFAP (astrocytes), pan-ELAVL(neurons), NESTIN (neural stem cells), Ki67, and OCT4. C: Percentage of cell-type-specific marker positive cells among HNA+ transplanted cells. NS; Not Significant 
A

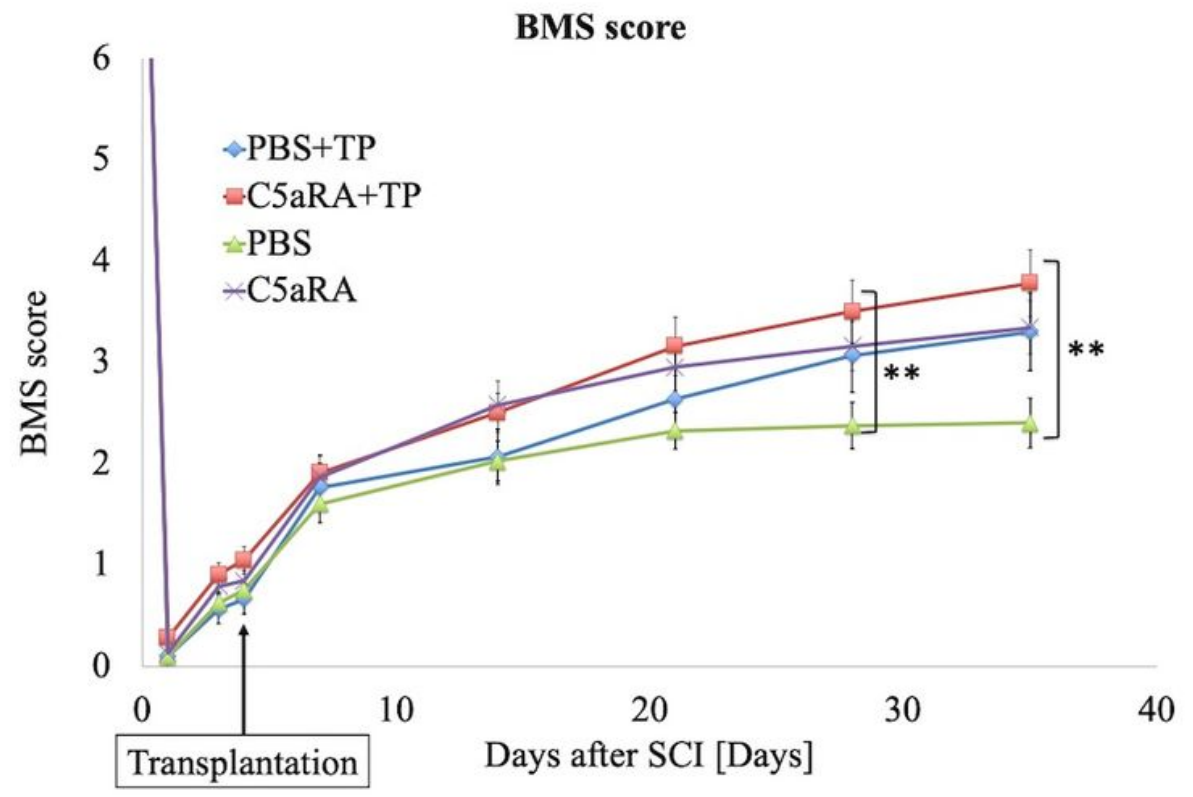

B

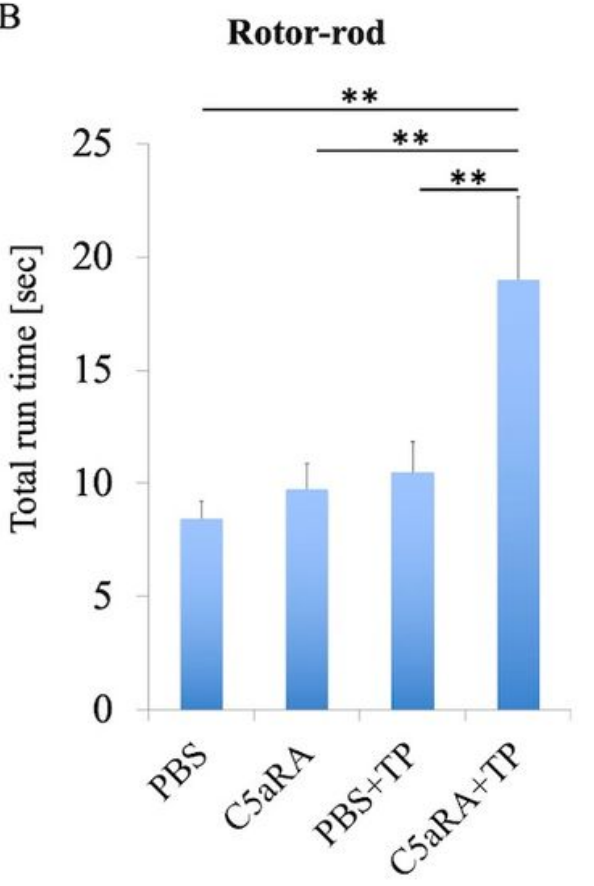

C

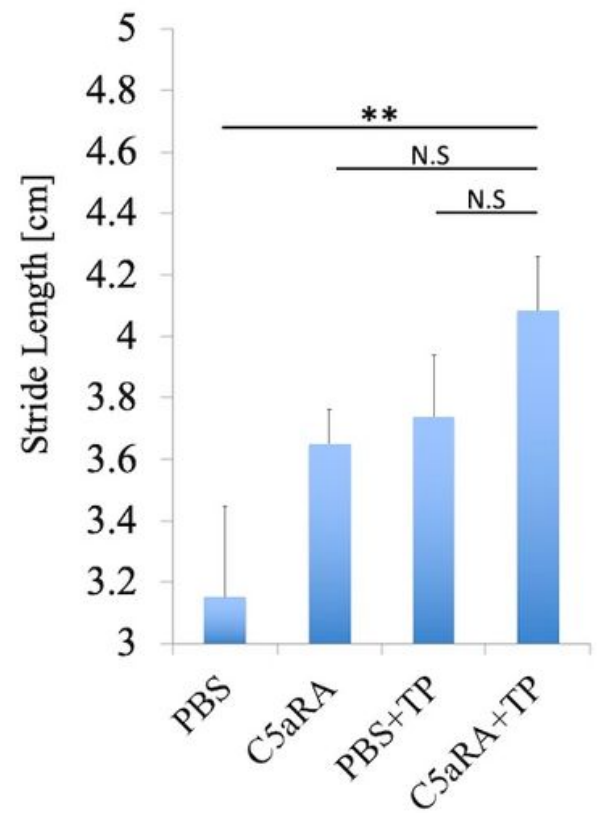

D

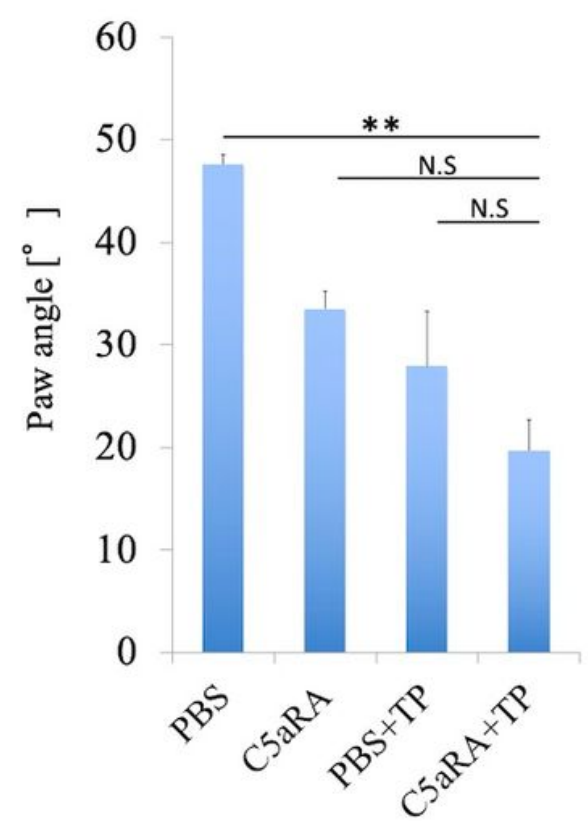

Figure 6

Hindlimb motor function after transplantation A: Hindlimb motor function was assessed weekly with the BMS score. ${ }^{* *} ; \mathrm{p}<0.05$. B: Total run time on the Rotor-rod in each group at 35 days after SCl. **;p<0.05 C-D: Stride length and paw angle acquired from Treadmill gait analyses using the DigiGait System in each group at 35 days after SCI. **;p<0.05

\section{Supplementary Files}


This is a list of supplementary files associated with this preprint. Click to download.

- Additionalfile1.tiff 